\title{
Six new species of Amblypsilopus Bigot (Diptera: Dolichopodidae: Sciapodinae) and a key to species of the Afrotropical mainland
}

\author{
Igor Ya. GRICHANOV ${ }^{\circledR}$ \\ All-Russian Institute of Plant Protection, Podbelskogo 3, St Petersburg, Pushkin, 196608, Russia. \\ Email: grichanov@mail.ru
}

urn:1sid:zoobank.org:author:5320AD3A-92D8-4820-8091-24802F8C8C06

\begin{abstract}
Six new species of Amblypsilopus Bigot, 1888 from the Afrotropical region are described and illustrated: A. gabonensis sp. nov. from Gabon, A. martini sp. nov., A. mufindiensis sp. nov. and A. udzungwensis sp. nov. from Tanzania, A. milleri sp. nov. from South Africa, and A. spiniscapus sp. nov. from Ivory Coast. Amblypsilopus gabonensis sp. nov. and A. spiniscapus sp. nov. are remarkable in having a setose antennal scape. Amblypsilopus martini sp. nov. and A. mufindiensis sp. nov. are peculiar in bearing very long setae on the antennal pedicel, mesonotum and scutellum. Amblypsilopus milleri sp. nov. is considered a member of the South African A. fasciatus species group despite its unmodified wing venation. The new species differ also from other similar representatives of the genus in the morphology of the male cercus and the male secondary sexual characters on the legs. The male of $A$. bevisi (Curran, 1927) is described for the first time. The following species described from females are considered doubtful (nomina dubia): A. flavicollis (Becker, 1923), A. rectangularis (Parent, 1937), A. sudanensis (Parent, 1939) and A. tropicalis (Parent, 1933). Amblypsilopus subfascipennis (Curran, 1926) has a strongly sinuate wing vein dm-m and is transferred to Chrysosoma Guérin-Méneville, 1831 (comb. nov.). Chrysosoma ungulatum Parent, 1941 from Príncipe with an almost straight vein dm-m is transferred to Amblypsilopus (comb. nov.). Chrysosoma centrale Becker, 1923 from Tanzania also has a straight wing vein $\mathrm{dm}-\mathrm{m}$ and modified fore tarsus, being very close in habitus to A. steelei Grichanov, 1996, and is also transferred to Amblypsilopus (comb. nov.). Chrysosoma asperum Parent, 1933 from South Africa has the same characters, is almost identical to South African A. bevisi and is also transferred here to Amblypsilopus (comb. nov.) and newly synonymized with A. bevisi (syn. nov.). Presently, 66 reliable species of Amblypsilopus are known from the Afrotropical region, including 37 from the Afrotropical mainland. A revised identification key to males of species of the Afrotropical mainland is provided. New records are given for some known species. The species diversity of the Afrotropical fauna and variability of morphological characters in the genus Amblypsilopus are briefly discussed.
\end{abstract}

Keywords. Sciapodinae, Amblypsilopus, Gabon, Ivory Coast, South Africa, Tanzania, Afrotropical mainland, key.

Grichanov I.Ya. 2022. Six new species of Amblypsilopus Bigot (Diptera: Dolichopodidae: Sciapodinae) and a key to species of the Afrotropical mainland. European Journal of Taxonomy 789: 49-80.

https://doi.org/10.5852/ejt.2022.789.1631 


\section{Introduction}

The genus Amblypsilopus Bigot, 1888 is known from all realms with ca 360 species worldwide (Grichanov 2017, 2021a, 2021b) and 66 Afrotropical species, including 28 species from Madagascar and adjacent islands (Grichanov 2021a, this paper). The genus is highly diverse in the tropics and radiated greatly in the Australasian (118), Oriental (84) and Neotropical (44) regions as well (Grichanov 2017). In the West Palaearctic, it is only represented by one possibly introduced European species and one species described from Turkey (Tonguç \& Grootaert 2013). The genus has penetrated into the East Palaearctic with at least 12 species known from the Palaearctic provinces of China (Yang et al. 2018) and three species found in Japan and Russian Primorye (Grichanov 2020a).

The last key to the then known Afrotropical Amblypsilopus species was published by Grichanov (1998). Later, four species of the genus were described from the Afrotropical continent, A parilis (Parent, 1931) was placed in synonymy with A. munroi (Curran, 1924) (Grichanov 1999, 2021b), and many new records have been published. See Grichanov $(2018,2020 b)$ for a catalogue of Amblypsilopus species known from Afrotropical countries. Grichanov (2021a) described eleven new species from Madagascar and provided a key to species from this and adjacent islands.

In this paper, six new species of the genus Amblypsilopus from Gabon, Ivory Coast, South Africa and Tanzania are described, new records are given for some known species, and a revised identification key to males of continental Afrotropical species is provided. The male of A. bevisi (Curran, 1927) is described for the first time.

\section{Material and methods}

Material used in this study was borrowed from the museums listed below. The newly described species of Amblypsilopus were photographed with a ZEISS Discovery V-12 stereo microscope and an AxioCam MRc5 camera. Preparations of the male genitalia were photographed with a ZEISS Axiostar stereo microscope and an AxioCam ICc3 camera, and are stored in glycerol in a microvial attached to the insect pin. Morphological terminology and abbreviations follow Cumming \& Wood (2017) and Grichanov \& Brooks (2017). The lengths of the podomeres and wing vein sections are given in millimetres. Body length is measured from the base of the antenna to the tip of abdominal segment 6 . Wing length is measured from the base to the wing apex.

The types of the new species and other material are mounted on pins (except as noted below) and housed at the following repositories:

BMSA $=$ National Museum, Bloemfontein, South Africa

NMSA $=$ KwaZulu-Natal Museum, Pietermaritzburg, South Africa

RBINS = Royal Belgian Institute of Natural Sciences, Brussels, Belgium

ZFMK = Zoologisches Forschungsmuseum Alexander Koenig, Bonn, Germany

ZIN $=$ Zoological Institute of the Russian Academy of Sciences, St Petersburg, Russia

ZMUC = Natural History Museum of Denmark, Zoological Museum, University of Copenhagen, Denmark

ZMUK = Zoologisches Museum, Universität Kiel, Kiel, Germany

ZMUM = Zoological Museum of Moscow State University, Moscow, Russia 


\title{
Results
}

\author{
Class Insecta Linnaeus, 1758 \\ Order Diptera Linnaeus, 1758 \\ Superfamily Empidoidea Latreille, 1804 \\ Family Dolichopodidae Latreille, 1809 \\ Subfamily Sciapodinae Becker, 1917 \\ Tribe Chrysosomatini Becker, 1918
}

Genus Amblypsilopus Bigot, 1888

\section{Type species}

Psilopus psittacinus Loew, 1861 [as "psitacinus Fabricius"] (original designation).

Diagnosis (based on Afrotropical species)

Arista-like stylus usually dorsal or dorsoapical on subrectangular postpedicel; wing usually hyaline, but sometimes with apical maculations; vein $\mathrm{M}_{1}$ with elbow-shaped bend, with its basal part forming right or acute angle with vein $\mathrm{M}_{1+2}$; vein $\mathrm{M}_{2}$ present at least as a fold in membrane (absent in A. lenga (Curran, 1929), but with $M_{1}$ forming strong $V$-shaped curvature); crossvein dm-m straight or slightly convex; legs elongate, with a few, usually weak major setae; anterior preapical seta absent on femora; male fore tarsus always modified or ornamented, often with thin elongated tarsomeres, bearing long setae or remarkable setulae; scutellum with 1 pair of strong setae, lateral pair of setae usually short, setula-like, or absent; male cercus without hook-shaped or articulated basoventral lobe (sometimes furcated from base). See also Bickel $(1994,2019)$ for a diagnosis of the genus.

\section{Notes}

Grichanov \& Brooks (2017) provided a key to all Afrotropical genera of the subfamily Sciapodinae and mentioned that the genus Amblypsilopus is poorly defined and probably polyphyletic. Males usually have modified and ornamented podomeres (male secondary sexual characters or MSSC). Females of closely related species are generally indistinguishable morphologically (e.g., Irwin 1974; Bickel 1994; Grichanov 2021a). Therefore, the following old species described poorly from females must be considered doubtful (nomina dubia): Amblypsilopus flavicollis (Becker, 1923) from Cameroon, A. rectangularis (Parent, 1937) from DR Congo, A. sudanensis (Parent, 1939) from Sudan and A. tropicalis (Parent, 1933) from DR Congo. The female of Sciapus subfascipennis Curran, 1926 from Uganda was placed in the genus Amblypsilopus by Bickel (1994), but was described with a strongly sinuate wing vein dm-m (Curran 1926: fig. 2) and must be transferred to Chrysosoma Guérin-Méneville, 1831 (comb. nov.). The latter genus is highly diverse in Central Africa (Grichanov 2018) with many species differing only in male characters. At present, Chrysosoma subfascipennis cannot be associated with males of other known species, being probably unrecognizable. In contrast, Chrysosoma ungulatum Parent, 1941 from Príncipe was described with an almost straight, slightly convex vein dm-m (Parent 1941: fig. 19) and must be transferred to Amblypsilopus (comb. nov.). Males of this species have enlarged claws (Parent 1941: fig. 18), similar to those in A. bipectinatus (Parent, 1934) and A. cuthbertsoni (Parent, 1937). Chrysosoma centrale Becker, 1923 from Tanzania also has straight wing vein dm-m, modified fore tarsus (Becker 1923), being very close in habitus to A. steelei Grichanov, 1996, and is also transferred to Amblypsilopus (comb. nov.). Chrysosoma asperum Parent, 1933, described by Parent (1934) from South Africa has the same characters, is almost identical to the South African Amblypsilopus bevisi (Curran, 1927) and is also transferred here to Amblypsilopus (comb. nov.) and newly synonymized with A. bevisi (syn. nov.). 


\section{Key to species of Amblypsilopus Bigot, 1888 from Afrotropical mainland (males)}

1. $\mathrm{R}_{2+3}$ and $\mathrm{R}_{4+5}$ fused at wing apex (Amblypsilopus fasciatus species group, in part)

- $\mathrm{R}_{2+3}$ and $\mathrm{R}_{4+5}$ not fused at wing apex

2. Postocellar hairs numerous (at least more than a single pair); antennal postpedicel dark brown; cercus elongate with flattened area at tip

- Postocellar hairs comprised of one pair; antennal postpedicel yellowish; cercus small with tapered tip

3. Wing heavily infuscate; vein $\mathrm{M}_{1}$ not recurved basally; apical sclerotized spot of wing tip not reaching posterior margin of wing (Irwin 1974: fig. 15; Grichanov 2011: fig. 223); body: $7.2 \mathrm{~mm}$ (South Africa)

A. stuckenbergorum (Irwin, 1974)

- Wing lightly infuscate; $M_{1}$ strongly recurved basally; apical sclerotized spot of wing tip reaching posterior margin of wing (Irwin 1974: fig. 14); body: $7.8 \mathrm{~mm}$ (South Africa)

A. retrovena (Irwin, 1974)

4. Wing with reduced apical sclerotized spot and dense patch of thickened macrotrichia (Irwin 1974: fig. 11); wing with two rows of hook-like setae below $\mathrm{M}_{1}$; cercus small with elongate base (Irwin 1974: fig. 8); body: $8.8 \mathrm{~mm}$ (South Africa)

A. fasciatus (Curran, 1924)

- Wing with well-developed apical sclerotized spot and no dense patch of thickened macrotrichia; wing without rows of hook-like setae; cercus small with short, rounded base

5. Arista-like stylus cylindrical at tip; upcurved portion of wing vein $\mathrm{M}_{1}$ beyond fork $\mathrm{M}_{1+2}$ with definite, thickened spot; $\mathrm{dm}-\mathrm{m}$ with two slightly thickened areas, these thickenings not forming distinct spots (Irwin 1974: fig. 13); body: $6.9 \mathrm{~mm}$ (South Africa)

A. bonniae (Irwin, 1974)

- Arista-like stylus horizontally spatulate at tip; upcurved portion of $M_{1}$ beyond fork $M_{1+2}$ slightly swollen, with darkened area; dm-m with two definite, swollen spots (Irwin 1974: fig. 12); body: $7.8 \mathrm{~mm}$ (South Africa)

A. macularivena (Irwin, 1974)

6. $\mathrm{M}_{2}$ absent; $\mathrm{M}_{1}$ with strong V-shaped curvature (Parent 1937: fig. 7 as in Sciapus barbipalpis); 4-4.5 mm (Liberia, Sierra Leone)

A. lenga (Curran, 1929)

- Venation normal

7. Antennal scape with 2-3 strong dorsal bristles (Fig. 1B-C) (Amblypsilopus abruptus species group, in part)

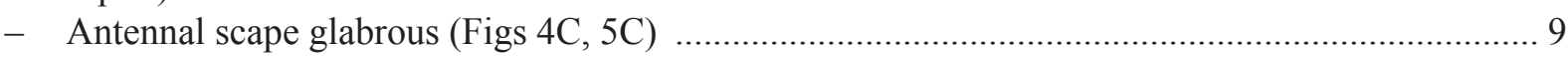

8. Fore basitarsus with posteroventral row of erect hooked hairs, as long as tarsomere width (Fig. 1C); hind tarsomeres 1-3 distinctly thickened (Fig. 1D) (Ivory coast); body: $4.2 \mathrm{~mm}$

A. spiniscapus sp. nov.

- Fore tarsomeres 1-2 with ventral rows of microscopic white hairs along entire length (Fig. 2D); hind tarsus simple (Gabon); body: $4.4 \mathrm{~mm}$ A. gabonensis sp. nov.

9. Scutellum with 15-20 long dorsal and marginal cilia in addition to pair of strong setae; antennal pedicel with very long dorsal and ventral setae (Figs 5C, 6C) (Tanzania) (Amblypsilopus mufindiensis species group)

- Scutellum with only pair of strong setae; antennal pedicel with short dorsal and ventral setae, about as long as postpedicel (Figs 3C, 4C) 
10. Mid tarsomeres 3-5 with only black elongate setulae (Fig. 5E); surstylus bilobate (Fig. 5H); body: $6 \mathrm{~mm}$

A. mufindiensis sp. nov.

- Mid tarsomeres 3-5 with white and black elongate setulae (Fig. 6F); surstylus trilobate (Fig. 6I); body: $6.5-7 \mathrm{~mm}$

A. martini sp. nov.

11. Legs practically unmodified, with only fore basitarsus with ventral row of about 5 fine setae, slightly longer than diameter of segment; cercus as long as epandrium, bifurcated at apex, with unequal lobes, densely covered with long setae (Grichanov 2021b: figs 7-8) (Gabon)

A. ruchini Grichanov, 2021

- Fore tarsus always modified, often with fore tarsomeres 4-5 flattened, white or bearing long setae, with remarkable setae on some other podomeres; cercus various

12. Fore coxa yellow; halters usually yellow; lower calypter usually with light setae ........................ 13

- Fore coxa black in at least basal forth; halters usually black-brown; lower calypter usually with black setae (Amblypsilopus abruptus species group, in part)

13. Face broadest at middle, wider than frons (e.g., Fig. 3B), 1.1-1.4 times as wide as high (South Africa) (Amblypsilopus fasciatus species group, in part)

- Face not wider than frons, gradually narrowed downward 15

14. Fore tibia and tarsus with erect pectination (Fig. 3D); mid femur with short ventral hairs; cercus with sparse long black setae along entire length, without flattened area at tip (Fig. 3F); body: $5 \mathrm{~mm}$......

A. bevisi (Curran, 1927)

- Fore tibia and tarsus without erect pectination; mid femur with at least 3 strong ventral bristles, as long as height of femur (Fig. 4E); cercus with comb of regular dorsal setae except for distal fifth, with flattened area at tip covered ventrally with microscopic white hairs (Fig. 4G); body: $6 \mathrm{~mm} \ldots$...

A. milleri sp. nov.

15. All coxae wholly yellow 16

- At least mid coxa with blackish-brown spot .................................................................................. 18

16. Cercus as large as epandrium, obovoid, with small middorsal tooth bearing 2 long setae (Grichanov 2021b: figs 5-6) (Gabon) A. korotyaevi Grichanov, 2021

- Cercus narrow, short or long

17. Thorax metallic green, metepimeron yellow; cercus narrow, short, densely covered with ventral hairs on distal half; body: $3.6 \mathrm{~mm}$ (Grichanov 1998: fig. 22) (DR Congo)

A. barkalovi Grichanov, 1998

- Thorax mostly yellow; cercus filiform, nearly 3 times as long as hypopygium, with short hairs (Grichanov 2011: fig. 226); body: 7-7.5 mm (South Africa) A. rosaceus (Wiedemann, 1824)

18. Antenna mostly yellow

- Antenna black

19. Fore basitarsus not enlarged; tarsomere 5 of fore tarsus enlarged, with comb of yellow setae, longer than tarsomere diameter; cercus trilobate from base (Grichanov 1996: fig. 3); body: $9.7 \mathrm{~mm}$ (DR Congo, Ethiopia, Kenya, Tanzania, Uganda)

A. basilewskyi (Vanschuytbroeck, 1960)

- Fore basitarsus enlarged, with ventral pile; other tarsomeres simple; cercus bilobate or simple ... 20

20. Fore basitarsus about half as long as 4 next tarsomeres combined; cercus bilobate at apex (Grichanov 1996: fig. 1); body: $6.2 \mathrm{~mm}$ (Kenya) A. steelei Grichanov, 1996

- Fore basitarsus as long as 4 next tarsomeres combined; cercus not lobate, hook-shaped; body: $4.5 \mathrm{~mm}$ (Tanzania) A. centralis Becker, 1923 comb. nov. 


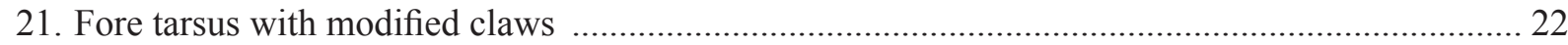

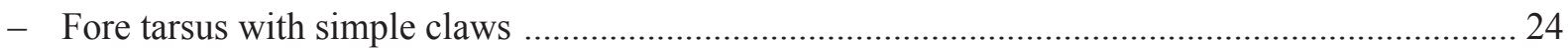

22. Mid tibia and basitarsus with anterior and ventral ciliation of thickened setulae, as long as tibia diameter; cercus simple, with 6 subapical setae, as long as cercus (Parent 1934: fig. 18); body: $6 \mathrm{~mm}$ (Kenya)

A. bipectinatus (Parent, 1934)

- Mid tibia with simple setulae; cercus various

23. Cercus elongate-triangular, narrow at apex, with 2 long middorsal cilia, as long as cercus (Parent 1937: fig. 11); body: $5 \mathrm{~mm}$ (Burundi, Tanzania, Zimbabwe)

A. cuthbertsoni (Parent, 1937)

- Cercus subtriangular, widest at apex, with wide apical excavation (Parent 1941: fig. 17); body $4.5 \mathrm{~mm}$ (Príncipe) A. ungulatum (Parent, 1941) comb. nov.

24. Fore femur with ventral brush of long dense curved yellow-brown hairs; tarsomere 5 of mid tarsus white; cercus bifurcated at apex (Grichanov 1996: fig. 5); body: $4.4 \mathrm{~mm}$ (Tanzania)

A. gorodkovi Grichanov, 1996

- Fore femur without such brush; cercus various

25. Wing with small dark apical spot (Parent 1929: fig. 121); cercus as long as epandrium, bandlike, truncated at apex (Parent 1929: fig. 120); body: 3 mm (DR Congo, Senegal)

A. nanus (Parent, 1929)

- Wing hyaline; cercus various

26. Lower calypter with white cilia; fore and mid tarsi with erect ciliation (Fig. 7D-E); mid tibia simple; surstylus much smaller than epandrium

- Lower calypter with black cilia; fore and mid tarsi without erect ciliation; mid tibia flattened dorsally and ventrally, devoid of setulae on flat sides; surstylus elongate

27. Postpedicel oval, with dorsoapical arista-like stylus; mid tibia without erect ciliation; cercus simple, with small distodorsal apophysis (Grichanov 1996: fig. 4); body: 4.3-4.6 mm (Angola, Gabon) .....

A. nartshukae Grichanov, 1996

- Postpedicel conoid, with apical arista-like stylus (Fig. 7C); mid tibia with erect ciliation; cercus with large middorsal tooth (Fig. 7H); body: $4.3 \mathrm{~mm}$ (Tanzania)

A. udzungwensis sp. nov.

28. Fore tibia flattened posterodorsally and anteroventrally, devoid of setulae on flat sides; mid tarsus with $1^{\text {st }}-4^{\text {th }}$ segments flattened anteriorly and posteriorly; cercus with short thick ventral process at middle (Grichanov 1999: fig. 15); body: 4 mm (DR Congo) A. weii Grichanov, 1999

- Fore tibia and mid tarsus simple; cercus with short narrow bifurcated ventral process at proximal third (Grichanov 1999: fig. 14); body: 7.25 mm (Cameroon, Ivory Coast) ......A. knorri Grichanov, 1999

29. At least fore femur with long brown-black ventral bristles

- Fore femur with white ciliation below, sometimes with a few dorsal or preapical black hairs, or bare

30. Fore femur with two fine black ventral setae on basal fourth, other femora bare (Grichanov et al. 2011: fig. 3); fore and mid femur black almost entirely or brown dorsally and yellow ventrally; cercus simple, with midventral projection (Parent 1936: fig. 9); body: 5 mm (DR Congo)

A. tenuicauda (Parent, 1936)

- Legs entirely black; all femora with a row of brown or black setae; cercus simple, with small tubercle (Parent 1936: fig. 1); body: 3 mm (Burundi, DR Congo, Nigeria) . A. disjunctus (Parent, 1936) 
31. Cercus short, usually broad, not much longer than epandrium .................................................... 32

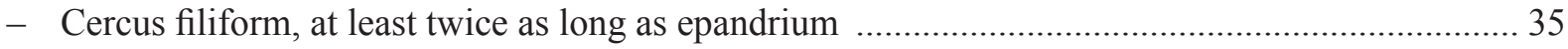

32. All femora bare; last three tarsomeres of hind tarsus flattened; body: $2.5 \mathrm{~mm}$ (DR Congo, Malawi)

- Femora with long white ventral hairs; last two tarsomeres of hind tarsus flattened; body longer than $3.5 \mathrm{~mm}$

33. Femora with ventral cilia, not longer than femur diameter; fore tibia and basitarsus with fine erect ciliation on dorsal side; cercus (Parent 1935: fig. 28); body: 3.5 mm (Mozambique, Zimbabwe) ....

A. miser (Parent, 1935)

- Femora with ventral cilia, longer than femur diameter; fore tibia and basitarsus without erect setulae

34. Fore basitarsus $3 / 4$ to $7 / 5$ as long as second tarsomere and $2 / 5$ to $2 / 3$ as long as rest tarsomeres from second to fifth; cercus (Grichanov 1996: fig. 8); body: 3.6-4.2 mm (Angola, DR Congo, Ethiopia, Gabon, Guinea, Ivory Coast, Nigeria, Senegal, South Africa, Tanzania, Zambia, Zimbabwe)

A. auratus (Curran, 1924)

- Fore basitarsus 1.5-2 times as long as second tarsomere and $2 / 3$ to $\% 10$ as long as tarsomeres from second to fifth; cercus (Grichanov 1996: fig. 9); body: 3.4-3.8 mm (Cameroon, DR Congo, Ethiopia, Kenya, Madagascar, Namibia, Nigeria, Togo, Zimbabwe) A. cilifrons (Parent, 1937)

35. All femora with white ventral hairs on basal half, longer than femur diameter; mid femur with white hairs turning into long black hairs on apical half of posteroventral surface; apical third of fore basitarsus with ventral pad of short hooked hairs; mid tibia with two short dorsal setae; cercus with long ventral cilia; surstylus strongly curved (Grichanov 1996: fig. 6); body: $4.5 \mathrm{~mm}$ (DR Congo, Kenya, Malawi, St Helena, Tanzania, Uganda, Zimbabwe) A. longifilus (Becker, 1923)

- Femora with short ventral hairs on basal half; fore tarsus with simple setulae; cercus with short hairs; surstylus long, almost straight (Grichanov 1996: fig. 7 as in Amblypsilopus parilis); body: $3.5 \mathrm{~mm}$ (Angola, DR Congo, Mozambique, Namibia, Nigeria, South Africa, Tanzania, Zimbabwe; Sri Lanka)

A. munroi (Curran, 1924)

(A. signatus Becker, 1923 from Malawi also keys here, and the two names may be synonymous)

Amblypsilopus abruptus species group

\section{Diagnosis}

See Bickel (1994) for a full diagnosis of the species group. The Afrotropical Amblypsilopus abruptus species group shares mostly primitive characters, such as the short antennae, broad face, mostly nonornamented and non-elongated legs, unmodified wing venation, usually dark body and femora, simple cercus and surstylus.

\section{Notes}

The Amblypsilopus abruptus species group is widespread throughout the Old World tropics. The Madagascan fauna numbers six mostly endemic species including A. cilifrons reported also from Cameroon, DR Congo, Ethiopia, Kenya, Namibia, Nigeria, Togo and Zimbabwe. The following species known from the Afrotropical mainland belong to the A. abruptus species group: A. auratus, A. cilifrons, A. disjunctus, A. longifilus, A. miser, A. munroi, A. perniger, A. signatus and A. tenuicauda. Amblypsilopus spiniscapus sp. nov. and A. gabonensis sp. nov. are also associated with the A. abruptus species group, differing from all other species of the genus in the presence of dorsal bristles on the antennal scape. Amblypsilopus auratus, A. cilifrons, A. longifilus and A. munroi are the commonest 
species known each from many countries on the continent, sometimes reported from the Atlantic (St Helena) and Indian Ocean islands (Madagascar, Sri Lanka). It seems that A. perniger, A. signatus, and A. tenuicauda have had no reliable records after their descriptions (Grichanov 2018).

Amblypsilopus auratus (Curran, 1924)

Chrysosoma auratum Curran, 1924: 217. Type locality: South Africa: KwaZulu-Natal, New Hanover.

Amblypsilopus auratus - Bickel 1994: 372.

\section{Material examined}

ETHIOPIA • 1 §̊; Amhara, Blue Nile; $10.08^{\circ}$ N, $38.19^{\circ}$ E; alt. 1050 m; 31 Jul. 2012; I. Gomyranov leg.; ZMUM.

GABON • 1 đ (in ethanol); Ntoum; Oct. 1985; A. Pauly leg.; yellow pan trap; plantation sur brûlis [on fire-site]; RBINS.

\section{Distribution}

Angola, DR Congo, Guinea, Ivory Coast, Nigeria, Senegal, South Africa, Tanzania, Zambia, Zimbabwe. First records from Ethiopia and Gabon.

Amblypsilopus cilifrons (Parent, 1937)

Chrysosoma cilifrons Parent, 1937: 126. Type locality: N Nigeria: Azare.

Amblypsilopus cilifrons - Grichanov 1996: 285.

\section{Material examined}

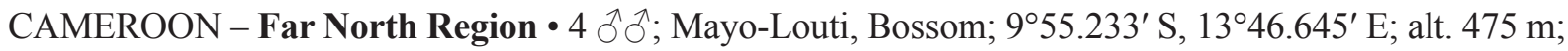
6 Aug. 2013; A.H. Kirk-Spriggs leg.; sweeping understory vegetation in deep shade; BMSA 1 § ; Benoue, Garoua town; $9^{\circ} 18.755^{\prime}$ S, $13^{\circ} 23.422^{\prime}$ E; alt. 206 m; 6 Aug. 2013; A.H. Kirk-Spriggs leg.; general sweeping

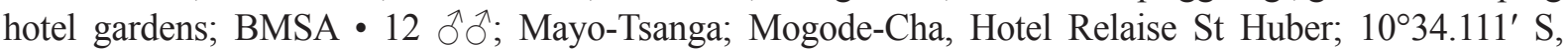
13³6.422' E; alt. 1001 m; 8-10 Aug. 2013; A.H. Kirk-Spriggs leg.; degraded savanna-forest; BMSA.

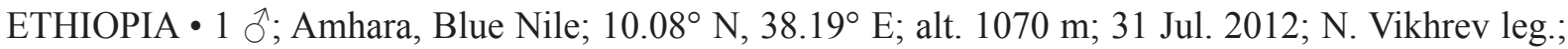

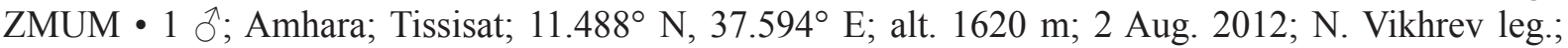
ZMUM.

ZIMBABWE 7 ภึ, 2 우 (in ethanol); North, $15 \mathrm{~km}$ SE of Muzarabani, Mavhurandonha W.A. [Wilderness Area]; 17-19 Dec. 1998; S. Bečwáŕ leg.; ZIN.

\section{Distribution}

DR Congo, Kenya, Madagasgar, Namibia, Nigeria, Togo. First records from Cameroon, Ethiopia and Zimbabwe.

\section{Amblypsilopus longifilus (Becker, 1923)}

Chrysosoma longifilum Becker, 1923: 28. Type locality: Tanzania: Arusha (originally published as "Katona-Arusha-In. und Mujenja").

Amblypsilopus longifilus - Bickel 1994: 352. 


\section{Material examined}

NAMIBIA 1 ơ; Katima Mulilo District, Mavunje campsite, Kwando River floodplain; $17^{\circ} 55.141^{\prime}$ S, $23^{\circ} 19.073^{\prime}$ E; alt. 945 m; 22-26 Nov. 2012; A.H. Kirk-Spriggs leg.; Malaise trap; BMSA.

TANZANIA • 2 えう; Nyassa Lake, Matema; $9.50^{\circ} \mathrm{S}, 34.01^{\circ}$ E; 15 Dec. 2015; N. Vikhrev leg.; ZMUM

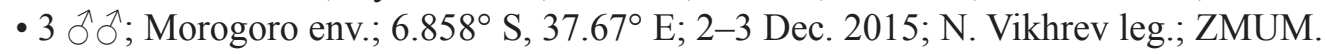

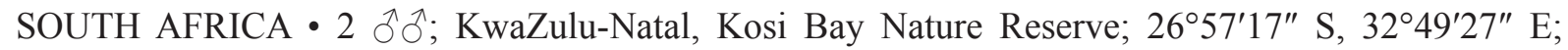
alt. 82 m; 13-17 Dec. 2010; A.H. Kirk-Spriggs leg.; woodland savanna; Malaise trap; BMSA.

ZIMBABWE $\bullet 2 \widehat{\partial} \widehat{\jmath}$ (in ethanol); North, $15 \mathrm{~km}$ SE of Muzarabani, Mavhurandonha W.A. [Wilderness Area]; 17-19 Dec. 1998; S. Bečwář leg.; ZIN.

\section{Distribution}

DR Congo, Kenya, Malawi, St Helena, Tanzania, Uganda. First records from Namibia, South Africa and Zimbabwe.

\section{Amblypsilopus munroi (Curran, 1924)}

Chrysosoma munroi Curran, 1924: 218. Type locality: South Africa, Eastern Cape, East London. Chrysosoma ernestum Curran, 1924: 218. Type locality: South Africa, Mpumalanga, Barberton. Chrysosoma parile Parent, 1931: 44. Type locality: "Afrique".

Amblypsilopus munroi - Bickel 1994: 352.

Amblypsilopus parilis - Bickel 1994: 373.

Amblypsilopus ernestus - Grichanov 1996: 286.

\section{Material examined}

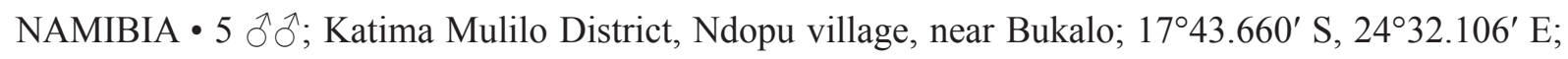
alt. 900 m; 20-23 Feb. 2012; A.H. Kirk-Spriggs leg.; degraded sand forest and cultivated plots; Malaise trap; BMSA.

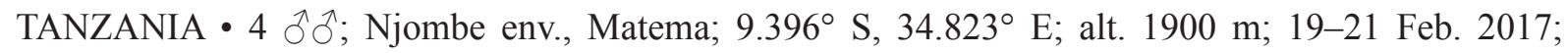

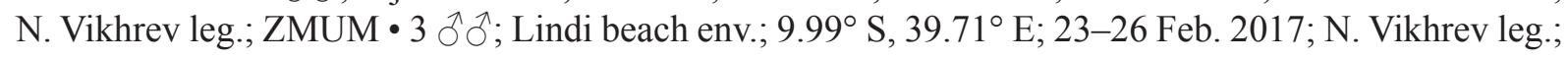
ZMUM.

\section{Distribution}

Angola, DR Congo, Mozambique, Namibia, Nigeria, South Africa, Tanzania, Zimbabwe; Oriental: Sri Lanka.

Amblypsilopus spiniscapus sp. nov. urn:lsid:zoobank.org:act:B28B1FEE-1946-4418-AB40-AEBFA8DAABC6

Fig. 1

\section{Diagnosis}

Amblypsilopus spiniscapus sp. nov. together with A. gabonensis sp. nov. belong to the A. abruptus species group, differing from all other species of the group in the presence of dorsal bristles on the antennal scape. The male cercus of the new species is bilobate, whereas other Afrotropical species of the group have a simple cercus, either short or long and filiform, at least 2 times as long as epandrium. The new species is very close to A. gabonensis sp. nov. in habitus, differing distinctly by its fore basitarsus 
bearing a posteroventral row of erect hooked hairs (Fig. 1C) and male cercus with differently shaped lobes (Fig. 1E). The male of Amblypsilopus gabonensis sp. nov. has simple hairs on the fore basitarsus (Fig. 2D).

\title{
Etymology
}

The Latin name of the species refers to the 'spiny scape' of the antenna.

\section{Material examined}

\section{Holotype}

IVORY COAST $-\lambda$ (dried from ethanol and mounted on pin); C.I. [= Côte d'Ivoire], $15 \mathrm{~km} \mathrm{~N}$ of Man, Cascades; $7^{\circ} 30^{\prime} \mathrm{N}, 8^{\circ} 30^{\prime} \mathrm{W}$; alt. 300 m; 20 Feb. 1998; Kassebeer and Hilger leg.; ZMUK.

\section{Description}

\author{
Male (Fig. 1A)
}

MeAsurements. Body length $4.2 \mathrm{~mm}$; antenna length $1.2 \mathrm{~mm}$; wing length $3.7 \mathrm{~mm}$; wing width $1.3 \mathrm{~mm}$.

HEAD. Frons shining greenish violet; 3-4 fine vertical setae and 1 strong postvertical bristle (broken); upper postocular setae black; lateral postocular setae white, uniserial; ventral postcranium covered with irregular white hairs; face shining greenish violet, broad, bulging under antennae, about as high as wide under antennae, at clypeus 2.5 times as wide as postpedicel; clypeus densely covered with short white hairs, large, as high as wide, separated from eyes; antenna (Fig. 1B) black, 1.2 times as long as height of head; scape slightly widened, vase-like, with 2 strong dorsal bristles, as long as scape; pedicel with ring of short bristles; postpedicel conoid, slightly longer than high (13/10), with short hairs; arista-like stylus middorsal, with 2 segments, microscopically haired; length $(\mathrm{mm})$ of scape, pedicel, postpedicel, stylus (segments 1 and 2), 0.13/0.08/0.13/0.06/0.96; palpus brown, with 2 black bristles; proboscis orange with white hairs.
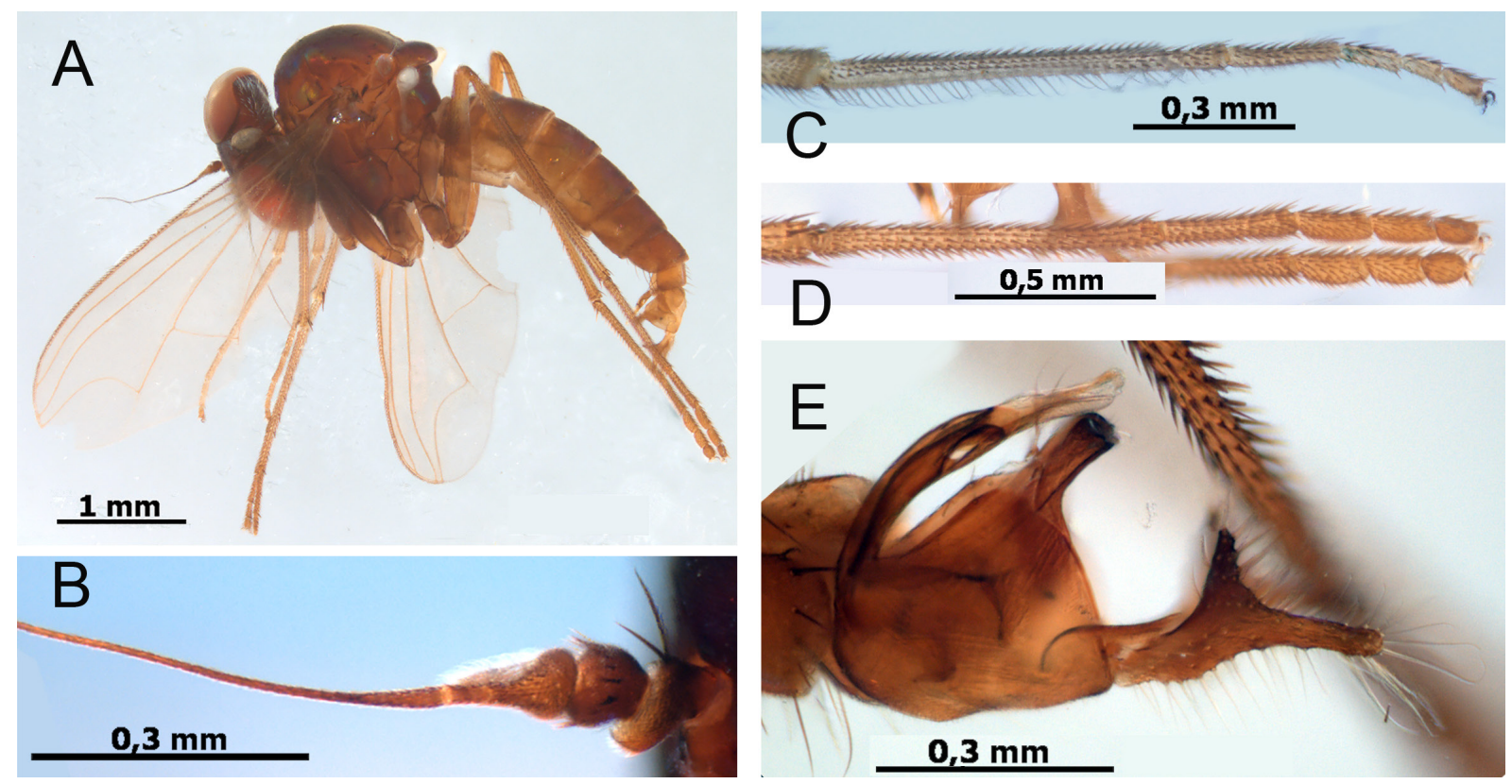

Fig. 1. Amblypsilopus spiniscapus sp. nov., holotype, $\widehat{\jmath}$ (ZMUK). A. Habitus. B. Antenna. C. Fore tarsus. D. Hind tarsus. E. Hypopygium after maceration, right lateral view. 
THORAX. Mesonotum and scutellum metallic blue-green, pleura blue-black, weakly grey pollinose; 2 strong dorsocentral bristles behind suture (broken) and 3 hair-like dorsocentrals anteriorly; 3 pairs of acrostichals; scutellum with 2 strong bristles (broken).

LEGS (somewhat discolored). With coxae and femora black, tibiae and basitarsi light brown; fore and mid coxae with white hairs and 2-4 white subapical bristles; hind coxa with 3 white setae of different length; all femora with double row of white ventral setae on basal half, at most as long as diameter of femur; mid femur with 3 posteroventral subapical setae; fore tibia without distinct setae; fore tarsomeres 1-2 with complete posterior row of setae, hooked on basitarsus, as long as diameter of segment, with ventral pad of white hairs along entire length (Fig. 1C); mid and hind tibiae with several short dorsal and ventral setae; hind tarsomeres 3-5 distinctly thickened, with ventral pad of microscopic hairs (Fig. 1D); femur, tibia and tarsomere (from first to fifth) length ratio (mm): fore leg: 0.84/0.97/0.88/0.24/0.13/0.09 /0.11, mid leg: 1.11/1.55/1.16/0.37/0.28/0.13/0.09, hind leg: 1.41/1.94/0.88/0.33/0.18/0.16/0.11.

WING (Fig. 1A). Widest at middle, greyish, veins brown; costa with simple setulae; $\mathrm{R}_{4+5}$ gently curved to $M_{1}$ in apical third; $M_{1+2}$ almost straight; $M_{1}$ with strong elbow, forming nearly right angle with $M_{1+2} ;$ ratio of parts of costa between $\mathrm{R}_{2+3}$ and $\mathrm{R}_{4+5}$ to those between $\mathrm{R}_{4+5}$ and $\mathrm{M}_{1}, 2.5 / 1$; crossvein dm-m straight; ratio of crossvein dm-m to apical part of $\mathrm{M}_{1+2}$ (fork-handle) to apical part of $\mathrm{M}_{4}, 0.51 / 0.58 / 0.25$; anal vein weak; anal lobe and alula well developed; anal angle acute; lower calypter blackish, with black cilia; halter dirty yellow.

ABDOMEN. Thin, shining blue-black, with black cilia and marginal setae; unmodified segments combined 1.7 times as long as thorax; segment 7 short, with black setae; hypopygium (Fig. 1E) brown-black, with blackish appendages; cercus as long as epandrium, bifurcated at middle, with unequal lobes, densely covered with light hairs; surstylus flattened, projected, with few short setae at apex; epandrial lobe small, with 1 long and 1 short apical setae; 1 short epandrial seta.

\section{Female}

Unknown.

\section{Remarks}

Two Amblypsilopus females were collected during the same expedition from the Zogouale locality $\left(7^{\circ} 25^{\prime} \mathrm{N}, 7^{\circ} 34^{\prime} \mathrm{W}\right)$, close to the $A$. spiniscapus sp. nov. type locality. They also have remarkable dorsal setae on the antennal scape, but cannot be associated with the new species, because those females bear dorsoapical stylus on the postpedicel, distinctly yellow fore coxa on distal half and yellow femora. They may belong to a different undescribed species.

Amblypsilopus gabonensis sp. nov. urn:lsid:zoobank.org:act:C17421EA-669F-4729-B699-5366CBFBC12E

Fig. 2

\section{Diagnosis}

Amblypsilopus gabonensis sp. nov. together with A. spiniscapus sp. nov. belong to the A. abruptus species group, differing from all other species of the group in the presence of dorsal bristles on the antennal scape. Male cercus of the new species is bilobate, whereas other Afrotropical species of the group have a simple cercus, either short or long and filiform, at least 2 times as long as epandrium. The new species is very close to $A$. spiniscapus sp. nov., differing distinctly by its fore basitarsus bearing simple hairs (Fig. 2D) and male cercus with differently shaped lobes (Fig. 2E). The male of Amblypsilopus spiniscapus sp. nov. has erect hooked hairs on the fore basitarsus (Fig. 1C). 


\section{Etymology}

The species is named after the country of origin.

\section{Material examined}

\section{Holotype}

GABON - $\widehat{\partial}$ (dried from ethanol and mounted on pin); Gamba, Ogoué Maritime; $2^{\circ} 42^{\prime} \mathrm{S}, 10^{\circ} 01^{\prime} \mathrm{E}$; alt. 25 m; 8 Jul. 2002; Tchignoumba, Tobi, Ditona leg.; ZIN.

\section{Additional material}

GABON 11 (damaged specimen in ethanol); same locality as for holotype; 3 Jun. 2002; Syssou, Ngoma and Moussavou leg.; ZIN.

\section{Description}

Male (Fig. 2A)

Somewhat lightened due to long-term storage in ethanol. Similar to A. spiniscapus sp. nov. in all respects except as noted.
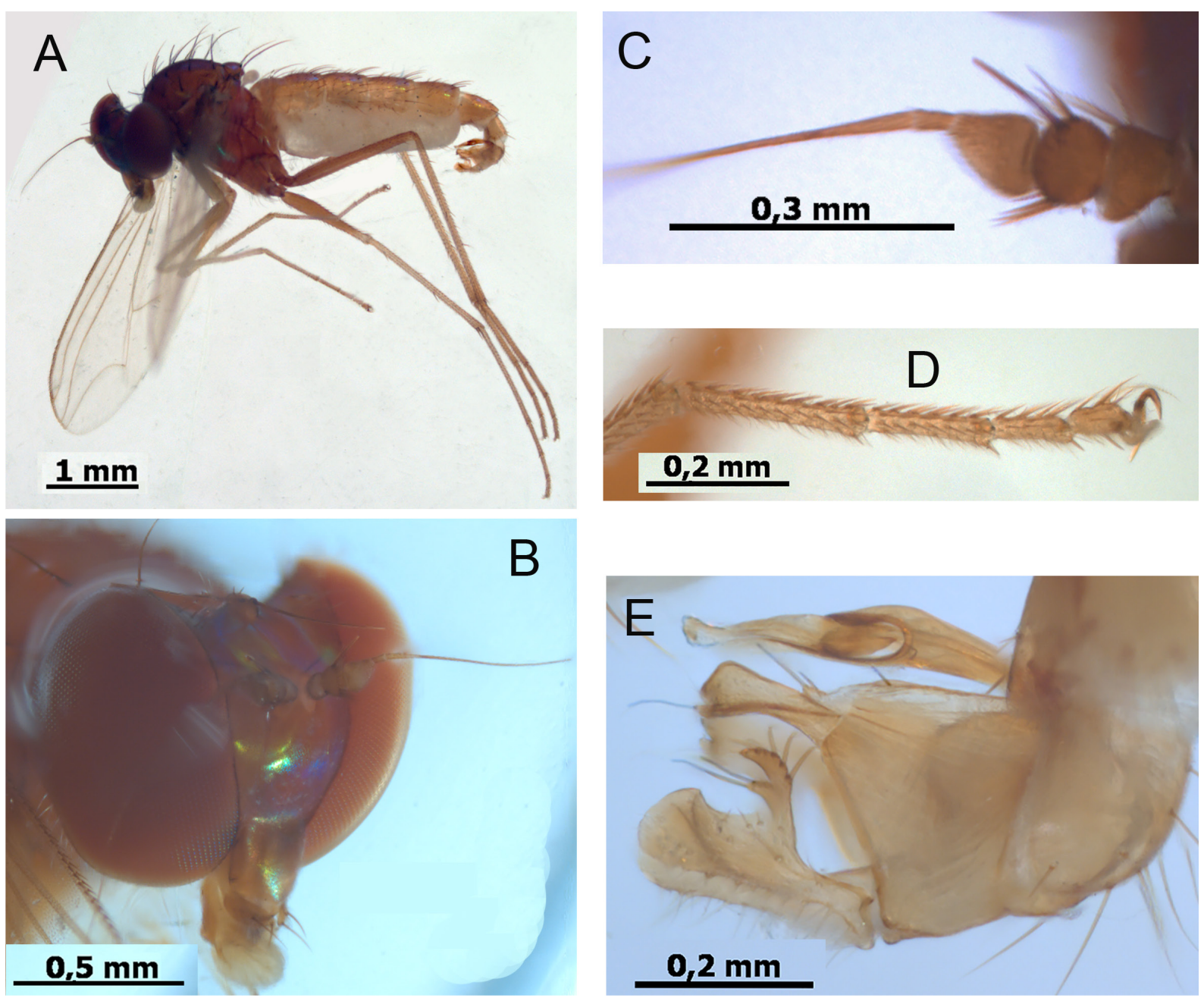

Fig. 2. Amblypsilopus gabonensis sp. nov., holotype, §̊ (ZIN). A. Habitus. B. Head. C. Antenna. D. Fore tarsomeres 2-5, lateral view. E. Hypopygium after maceration, left lateral view. 
Measurements. Body length $4.4 \mathrm{~mm}$; antenna length $1.2 \mathrm{~mm}$; wing length $3.8 \mathrm{~mm}$; wing width $1.2 \mathrm{~mm}$.

HeAd (Fig. 2B). Frons with 5 fine black vertical setae and 1 strong postvertical bristle; face at clypeus 2 times as wide as postpedicel; antenna (Fig. 2C) about as long as height of head; scape slightly widened, vase-like, with 3 strong dorsal bristles of different length, at most as long as scape; pedicel with ring of short bristles, with 1 strong dorsoapical bristle; postpedicel conoid, as long as high; arista-like stylus dorsoapical; length ( $\mathrm{mm}$ ) of scape, pedicel, postpedicel, stylus (segments 1 and 2), 0.08/0.07/0.09/0.04/0.91.

Thorax. Mesonotum with 2 strong dorsocentral bristles behind suture and 3 hair-like dorsocentrals anteriorly; 3 pairs of acrostichals decreasing in length anterior; scutellum with 2 strong bristles.

LEGS (discolored). With coxae and femora brown, tibiae and tarsi yellow to brownish; fore and mid coxae with white hairs and 2-4 white subapical bristles; hind coxa with 5 white setae of different lengths; all femora with double row of white ventral hairs on basal half or third, shorter than diameter of femur; fore and mid femur with 5 short black posteroventral subapical setae; fore tarsomeres 1-2 with ventral rows of microscopic white hairs along entire length (Fig. 2D); mid and hind tibiae with several short dorsal and ventral setae, each with 1-2 distinct anterodorsal bristles; hind tarsus simple with only segment 5 slightly thickened; femur, tibia and tarsomere (from first to fifth) length ratio (mm): fore leg: 1.09/1.2/0.71/0.28 /0.17/0.13/0.8, mid leg: 1.24/1.58/1.12/0.37/0.25/0.11/0.1, hind leg: 1.41/2.05/0.77/0.37/0.21/0.14/0.09.

WING. Ratio of parts of costa between $\mathrm{R}_{2+3}$ and $\mathrm{R}_{4+5}$ to those between $\mathrm{R}_{4+5}$ and $\mathrm{M}_{1}, 2.1 / 1$; ratio of crossvein dm-m to apical part of $\mathrm{M}_{1+2}$ (fork-handle) to apical part of $\mathrm{M}_{4}, 0.51 / 0.59 / 0.26$.

AвDomen. Unmodified segments combined 2 times as long as thorax; cercus (Fig. 2E) nearly as long as epandrium, bifurcated at middle, with unequal lobes; dorsal lobe broad, with short setae at apex; ventral lobe narrow, hooked, with row of 6 strong setae; surstylus flattened, projected, with 1 long and few short setae at apex; epandrial lobe small, with 1 long and 1 short apical setae; 1 short epandrial seta.

\section{Female}

Unknown.

Amblypsilopus fasciatus species group

\section{Diagnosis}

Bickel (1994) considered the Amblypsilopus fasciatus species group to be equivalent to the South African genus Sciopolina Curran, 1924, treated in Irwin (1974). The group is defined primarily by a male wing modification (MSSC), i.e., wing veins $\mathrm{R}_{2+3}$ and $\mathrm{R}_{4+5}$ are fused apically, and the wing apex has a more or less distinct apical sclerotized spot. The other morphological characters, including the hypopygium, are well within the range of variation found in the genus (Bickel 1994). Nevertheless, the here newly described males of $A$. bevisi and A. milleri have unmodified wings, but belong to the A. fasciatus species group on the basis of the morphology of the hypopygium and other characters listed below. Therefore, the group as a whole must be considered a part of the A. pallidicornis lineage as defined by Bickel (1994). The complex of characters uniting species of that group are as follows (after Irwin 1974): body ground colour brilliant metallic yellowish-green, blue-green or purple-red, and brown; face broad, more or less bulging under antennae, with more or less protruding clypeus; antenna usually short (but very long in A. milleri); legs elongate, mainly yellow, poorly ornamented; wing anal lobe well developed and anal angle acute in both sexes (wing anal lobe often reduced in males of other species groups of Amblypsilopus); male cercus swollen at base, elongate and narrow, bearing rows of long setae (male cercus often furcate in other species of the genus). The male cercus in A. bevisi is almost identical 
to that in A. bonniae and A. macularivena, and the male cercus in A. milleri is quite similar to that in A. fasciatus, A. retrovena and A. stuckenbergorum (figured by Irwin 1974).

\section{Notes}

The Amblypsilopus fasciatus species group is confined to South Africa (KwaZulu-Natal, Mpumalanga, Western Cape and bordering area of Eastern Cape). The following species belong to the A. fasciatus species group: A. bevisi, A. bonniae, A. fasciatus, A. macularivena, A. milleri, A. retrovena and A. stuckenbergorum. Amblypsilopus milleri with the long male antenna may relate with the Madagascan A. pallidicornis species group (see Grichanov 2021a). Amblypsilopus stuckenbergorum is the commonest species of the group, inhabiting montane forest and grassland zones of the eastern portion of southern Africa (Irwin 1974).

Amblypsilopus bevisi (Curran, 1927)

Fig. 3

Sciapus bevisi Curran, 1927: 11. Type locality: South Africa: Natal, Durban, Umbilo.

Chrysosoma asperum Parent, 1933: 43 (in key) (description: Parent 1934: 114), syn. nov. Type locality:

South Africa: Cape Province, Somerset East.

Sciopolina bevisi - Irwin 1974: 249.

Amblypsilopus bevisi - Bickel 1994: 373.

Amblypsilopus asper - comb. nov.

\section{Diagnosis}

Amblypsilopus bevisi male is close to A. milleri sp. nov. in habitus, differing from the latter in the fore tibia and tarsus with erect pectination (Fig. 3D); the mid femur with short ventral hairs; the cercus swollen at base, narrow distally, with sparse long black setae along the entire length, without flattened area at the tip (Fig. 3F-G). Amblypsilopus milleri sp. nov. differs from A. bevisi in the fore tibia and tarsus without erect pectination; the mid femur with at least 3 strong ventral bristles, as long as height of femur; the cercus elongate, with a comb of regular dorsal setae except for distal fifth, with a flattened area at tip covered ventrally with microscopic white hairs (Fig. 4H).

\section{Material examined}

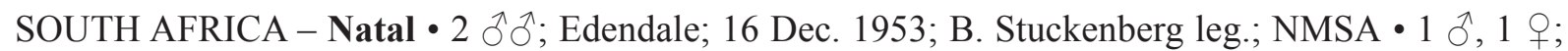
Cathedral Peak area; 1 Jan. 1954; B. Stuckenberg leg.; in indigenous forest ( $ð$ ), from open grassland

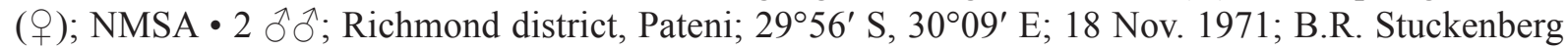
and M.E. Irwin leg.; temperate forest; NMSA $\bullet 2 \hat{\jmath} \widehat{\partial}, 4$ 우; $17 \mathrm{~km}$ E of Mooi River, "Lanner Veane";

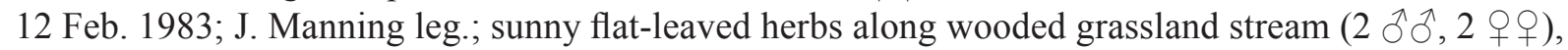
Leucosidea Eckl. \& Zeyh. scrub-streamside herbs (2 qo+); NMSA • 1 §ं; Injisuti, Drakensberg; $29^{\circ} 06^{\prime} 35^{\prime \prime}$ S, $29^{\circ} 26^{\prime} 33^{\prime \prime}$ E; alt. 1632 m; 6 Dec. 1998; A.P. Leftwich leg.; montane forest; NMSA. KwaZulu-Natal • 1 ô (specimen in ethanol); Royal Natal Nature Reserve, Mahal Camp; alt. 1450 m; $28^{\circ} 41.27^{\prime}$ S, $28^{\circ} 56.86^{\prime}$ E; 24 Nov.-6 Dec. 2005; Mostovsky leg.; yellow pan trap; NMSA 1 1 (specimen in ethanol); Cathedral Peak Natural Reserve, Rainbow Gorge; alt. $1480 \mathrm{~m}$; 28 $57.6^{\prime} \mathrm{S}$,

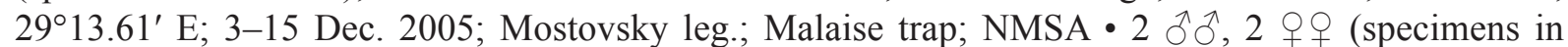
ethanol); Pietermaritzburg, Karkloof; 29¹9.1' S, 30¹5.5' E; alt. 1325 m; 22 Dec. 2005-18 Mar. 2006; Mostovsky leg.; Malaise trap; NMSA $12 \hat{\jmath} \widehat{\partial}, 12$ 우 (specimens in ethanol); Cathedral Peak Natural Reserve, Rainbow Gorge; $28^{\circ} 57.6^{\prime}$ S, $2^{\circ} 13.61^{\prime}$ E; alt. 1480 m; 18 Oct.-28 Feb. 2007; Mostovsky leg.; Malaise trap; NMSA. 


\section{Description}

Male (Fig. 3A)

MeAsurements. Body length $4.3 \mathrm{~mm}$; antenna length $1.2 \mathrm{~mm}$; wing length $4.5 \mathrm{~mm}$; wing width $1.5 \mathrm{~mm}$.

HEAD (Fig. 3B). Frons greenish black, white pollinose; 1 strong anterior vertical bristle; 1 strong postvertical bristle; upper postocular setae black, short; lateral postocular setae white, uniserial; ventral postcranium covered with long irregular white hairs; face densely silvery-white pollinose, broadest at middle, wider than frons (3/2), bulging, 1.1 times as wide as high, under antennae 3.5 times as wide as postpedicel; clypeus densely covered with short white hairs, projected, 1.1 times as wide as high, separated from eyes; antenna (Fig. 3C) 1/4 as long as body, brown; scape simple; pedicel rounded, with ring of short bristles; postpedicel conoid, as long as high (10/9), with short hairs; arista-like stylus dorsoapical, microscopically haired; length $(\mathrm{mm})$ of scape, pedicel, postpedicel, stylus (segments 1 and 2), 0.06/0.07/0.10/0.04/0.93; proboscis and palpus orange-yellow, with white hairs; palpus with 2 black setae.

THorax. Mesonotum and scutellum metallic blue-green, weakly grey pollinose; pleura blue-black, white pollinose; metepimeron yellow; 5-6 strong dorsocentral bristles gradually decreasing in size anteriorly; acrostichals strong, nearly as long as dorsocentrals, 5 pairs gradually decreasing in size anteriorly and several minute setae on anterior slope; scutellum with 2 strong bristles and 2 minute setae laterally.

Legs. Mostly yellow; mid coxa partly orange; tarsi brownish to brown from tip of basitarsi; fore and mid coxae with white hairs and 2-3 brown subapical setae; hind coxa with 4-5 fine yellow setae at middle; fore leg (Fig. 3D) along entire length with dorsal, ventral and lateral rows of semi-erect setulae, not longer than diameter of corresponding podomere; mid and hind femora with very short ventral hairs; mid tibia with 2 short anterodorsals and 2 short posterodorsals, with 1 midventral short seta; mid tarsus simple, cylindrical; basitarsus with few short ventrals; hind tibia with several short dorsal and ventral setae; femur, tibia and tarsomere (from first to fifth) length ratio (mm): fore leg: 1.16/1.42/1.44/0.6/0.49 /0.32/0.19, mid leg: 1.3/1.83/1.38/0.49/0.37/0.22/0.11, hind leg: 1.8/2.65/0.95/0.62/0.4/0.29/0.15.

WING (Fig. 3E). Almost hyaline, veins brown; $R_{4+5}$ gently curved to $M_{1}$ on apical third; $M_{1+2}$ almost straight; $M_{1}$ with strong elbow, forming obtuse angle with $M_{2}$; ratio of parts of costa between $R_{2+3}$ and $R_{4+5}$ to those between $\mathrm{R}_{4+5}$ and $\mathrm{M}_{1}, 3 / 1$; crossvein dm-m almost straight; ratio of crossvein $\mathrm{dm}-\mathrm{m}$ to apical part of $\mathrm{M}_{1+2}$ (fork-handle) to apical part of $\mathrm{M}_{4}, 56 / 86 / 53$; anal vein and lobe distinct; anal angle acute; alula present; lower calypter yellow with black apex, with fan of white setae; halter yellow with brownish knob.

ABDomen. Thin, 1.3 times as long as head and thorax combined, with short white hairs and long black marginal setae; segment 1 brown dorsally, yellow laterally, with white hairs and setae; unmodified segments shining bluish green, black posteriorly along sutures; segments 7 and 8 dark brown; segment 8 with white cilia; hypopygium (Fig. 3F) brown; hypandrium brown; cercus dirty yellow, 1.3 times as long as epandrium, broader at base, narrow distally, with strong black outer bristles (Fig. 3G), with short light hairs dorsally and longer light hairs ventrally; surstylus projected, moderately short and narrow, with short apical process and 4 long ventral setae; 3 long epandrial setae.

\section{Female}

Similar to male except lacking male secondary sexual characters. Females examined have no significant difference from the original description (Curran 1927) and subsequently published diagnosis (Irwin 1974) of Amblypsilopus bevisi.

\section{Remarks}

Amblypsilopus bevisi was described from a single female that was collected in a coastal forest in the KwaZulu-Natal Province of the Republic of South Africa. Irwin (1974) studied the holotype, transferred 
the species to the genus Sciopolina Curran, 1924 (now Amblypsilopus fasciatus species group), measured and diagnosed the specimen, and considered it close to A. macularivena. However, females of the $A$. fasciatus species group (with modified male wings) are poorly distinguished from subequal in size females of some other species groups. Additional specimens of $A$. bevisi have never been reported. Abundant material collected from seven localities in the KwaZulu-Natal Province (NMSA) compelled me to associate it with this species.
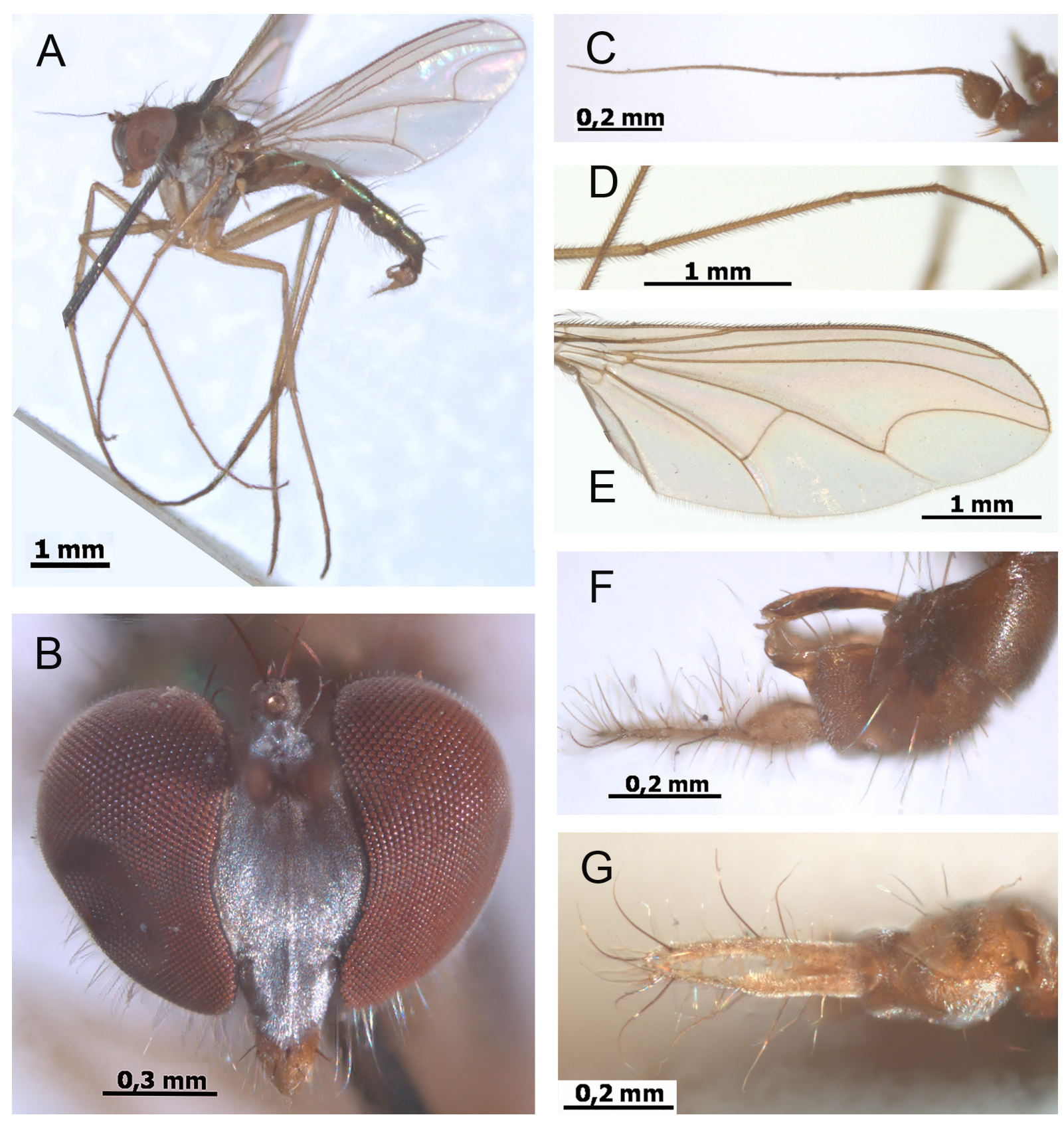

Fig. 3. Amblypsilopus bevisi (Curran, 1927), ô, Natal, Edendale (NMSA). A. Habitus. B. Head. C. Antenna. D. Fore tarsus. E. Wing. F. Hypopygium, left lateral view, dry. G. Hypopygium, dorsal view, dry. 
New material of $A$. bevisi collected from the KwaZulu-Natal Province stimulated the re-examination of the description of Chrysosoma asperum Parent, 1933 (Parent 1934). The latter species was described from the Eastern Cape Province of South Africa and has never been reported again. As it turned out, the species corresponds with the generic concept of Amblypsilopus, and its description is almost identical in all respects with the males of $A$. bevisi described above. Therefore, Chrysosoma asperum is placed here in synonymy with A. bevisi. The widespread polyzonal Chrysosoma tricrinitum Parent, 1933 is now the only representative of the genus Chrysosoma in South Africa (Grichanov 2018).

\section{Distribution}

South Africa (Eastern Cape, KwaZulu-Natal).

Amblypsilopus milleri sp. nov. urn:lsid:zoobank.org:act:1C5CBD0D-34DE-4714-BF5E-2BF70F5B5A8F

Fig. 4

\section{Diagnosis}

Amblypsilopus milleri sp. nov. is close to A. bevisi in habitus, differing from the latter in the fore tibia and tarsus without erect pectination; the mid femur with at least 3 strong ventral bristles, as long as height of femur (Fig. 4E); the cercus elongate, with comb of regular dorsal setae except for distal fifth, with flattened area at tip covered ventrally with microscopic white hairs (Fig. 4G-H). Amblypsilopus bevisi is distinguished by the fore tibia and tarsus with erect pectination (Fig. 3D); the mid femur with short ventral hairs; the cercus broader at base, narrow apically, with sparse long black setae along entire length, without flattened area at tip (see above) (Fig. 3F-G).

\section{Etymology}

The species is named for one of the collectors of the types, Dr R.M. Miller (NMSA).

\section{Material examined}

Holotype

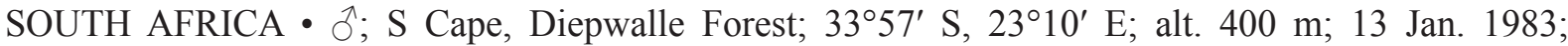
R.M. Miller leg.; NMSA.

\section{Paratypes}

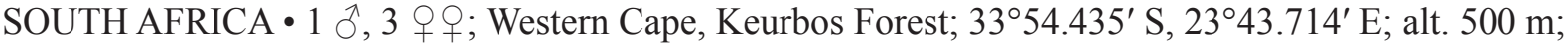
28-30 Mar. 2009; A.H. Kirk-Spriggs and S. Otto leg.; indigenous montane forest; Malaise trap; BMSA.

\section{Description}

Male (Fig. 4A)

MEASUREMENTS. Body length $6.4 \mathrm{~mm}$; antenna length $5.1 \mathrm{~mm}$; wing length $6.3 \mathrm{~mm}$; wing width $2 \mathrm{~mm}$.

HeAD (Fig. 4B). Frons greenish black, white pollinose; 1 anterior vertical hair; 1 strong postvertical bristle; upper postocular setae black, short; lateral postocular setae white, uniserial; ventral postcranium covered with long irregular white hairs; face densely silvery-white pollinose, broadest above middle, wider than frons (5/4), bulging, 1.4 times as wide as high, under antennae about 5 times as wide as postpedicel; clypeus densely covered with short white hairs, projected, wider than high (4/3), separated from eyes; antenna (Fig. 4C) 5/6 as long as body, with orange-brown scape and pedicel; scape swollen, vase-like; pedicel rounded, with ring of short bristles; postpedicel brown, small, conoid, 1.3 times as long as high, with short hairs; arista-like stylus black, apical, glabrous, one-segmented; length $(\mathrm{mm})$ of 
scape, pedicel, postpedicel, stylus, 0.12/0.11/0.16/4.76; proboscis orange; palpus blackish, with white and brown hairs.

THORAX. Mesonotum orange with metallic reflection; scutellum shining greenish blue; pleura brownish orange, white pollinose; metepimeron yellow; 2 strong posterior dorsocentral bristles and 3 hair-like setae anteriorly with strongest posterior pair; acrostichals long and strong, 5 pairs gradually decreasing in size anteriorly; scutellum with 2 strong bristles and 2 minute setae laterally.
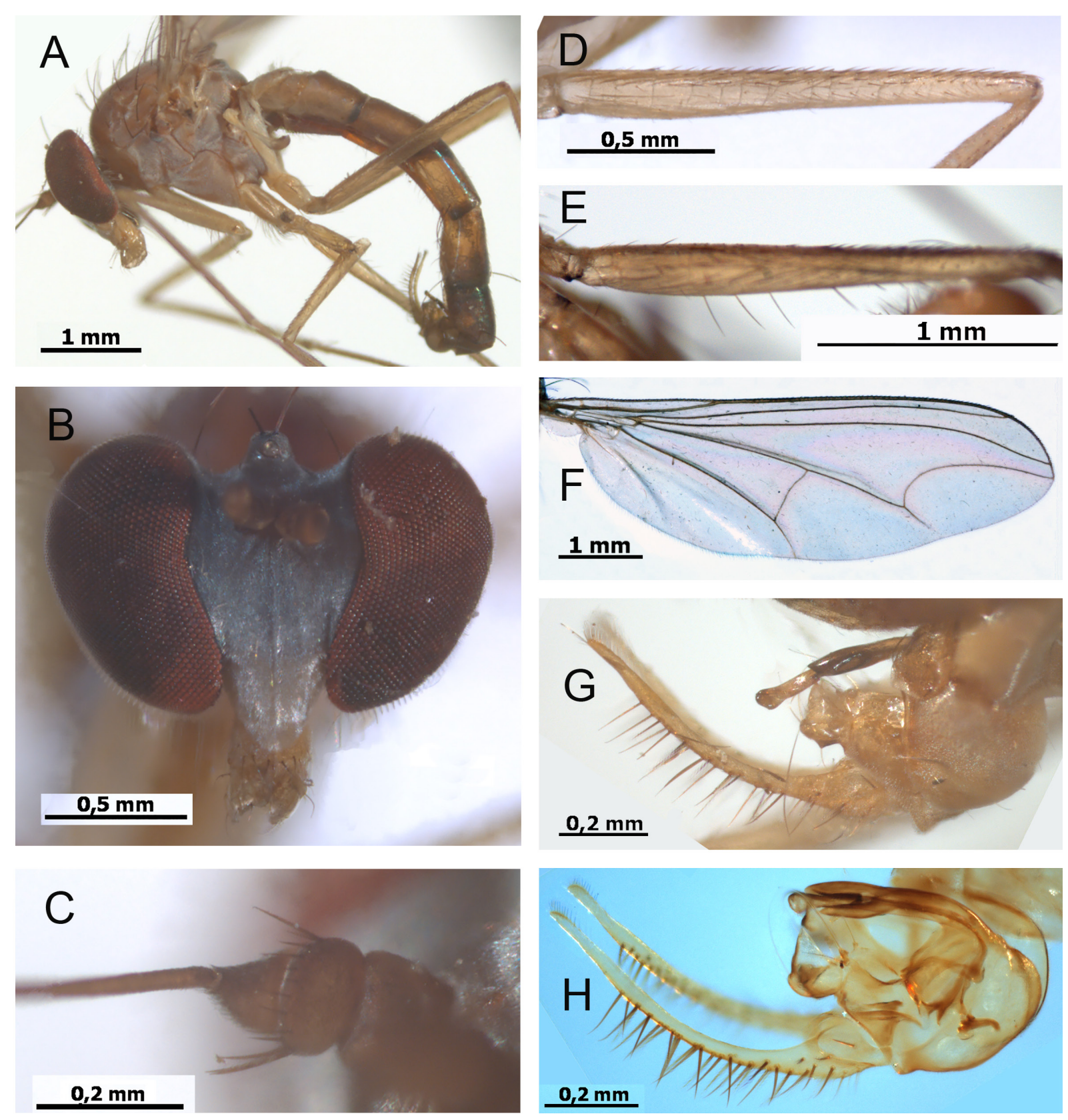

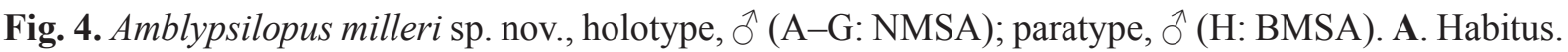
B. Head. C. Antenna. D. Fore femur and base of fore tibia. E. Mid femur. F. Wing. G. Hypopygium, left lateral view, dry. H. Hypopygium after maceration, left lateral view. 
Legs. Mostly yellow; tarsi brownish to brown from tip of basitarsi; fore and mid coxae with white hairs and 2-3 brownish subapical setae; hind coxa with 4-5 fine yellow setae at middle; fore (Fig. 4D) and hind legs simple, without remarkable setae or hairs; mid femur (Fig. 4E) with posteroventral row of 5-6 fine dark setae, at most as long as femur height; mid tibia with 2 short anterodorsals and 2 short posterodorsals, without ventral setae; mid tarsus simple, cylindrical; femur, tibia and tarsomere (from first to fifth) length ratio (mm): fore leg: 1.63/1.96/3.06/0.74/0.56/0.29/0.13, mid leg: 1.82/2.67/2.31/0.75/0.49/0.29/0.15, hind leg: $2.38 / 3.54 / 1.55 / 0.9 / 0.54 / 0.3 / 0.14$.

WING (Fig. 4F). Almost hyaline, veins brown; $\mathrm{R}_{4+5}$ gently curved to $\mathrm{M}_{1}$ on apical third; $\mathrm{M}_{1+2}$ almost straight; $M_{1}$ with strong elbow, forming obtuse angle with $M_{2}$; ratio of parts of costa between $R_{2+3}$ and $\mathrm{R}_{4+5}$ to those between $\mathrm{R}_{4+5}$ and $\mathrm{M}_{1}, 4 / 1$; crossvein dm-m almost straight; ratio of crossvein $\mathrm{dm}-\mathrm{m}$ to apical part of $\mathrm{M}_{1+2}$ (fork-handle) to apical part of $\mathrm{M}_{4}, 73 / 125 / 54$; anal vein and lobe distinct; anal angle acute; alula present; lower calypter yellow with black apex, with fan of white setae; halter yellow with brownish knob.

ABDOMEN. Thin, 1.8 times as long as head and thorax combined, with short white hairs and long black marginal setae; segment 1 yellow, with white hairs and setae; unmodified segments mostly orange-brown (holotype) or brownish yellow (paratype), becoming darker posteriorly, black posteriorly along sutures, shining green dorsally; segments 7 and 8 brownish yellow; segment 8 with short hairs; hypopygium (Fig. 4G) yellow; hypandrium brown; cercus yellow, broader at base, narrow apically, about 2 times as long as epandrium, with comb of regular dorsal setae except for distal fifth, with flattened area at tip covered ventrally with microscopic white hairs; surstylus projected, broad and relatively short, subtriangular, with few long dorsal and distal setae; 3 long pedunculate epandrial setae (Fig. 4H).

\section{Female}

MeAsurements. Body length $4.2 \mathrm{~mm}$; antenna length $1.8 \mathrm{~mm}$; wing length $4.5 \mathrm{~mm}$; wing width $1.6 \mathrm{~mm}$.

Similar to male except lacking male secondary sexual characters. Frons with strong and long anterior vertical seta; face under antennae about 2 times as wide as postpedicel; mesonotum with 6 strong dorsocentrals, without acrostichals; fore basitarsus as long as fore tibia and 2.5 times as long as tarsomere 2 .

\section{Ecology}

According to type specimen labels, imagos inhabit mountain forests at $400-500 \mathrm{~m}$ above sea level at the southern border of Eastern Cape and Western Cape Provinces of the Republic of South Africa.

Amblypsilopus stuckenbergorum (Irwin, 1974)

Sciopolina stuckenbergorum Irwin, 1974: 236. Type locality: South Africa: Natal, Pietermaritzburg, Town Bush.

Amblypsilopus stuckenbergorum - Bickel 1994: 373.

\section{Material examined}

SOUTH AFRICA - 3 $\widehat{\partial}, 2$ 우 (specimens in ethanol); KwaZulu-Natal, Cathedral Peak Natural Reserve, Rainbow Gorge; alt. 1480 m; 28 57.6' S, 29²13.61' E; 14 Dec. 2005-29 Jan. 2006; Mostovsky leg.; Malaise trap; NMSA.

\section{Distribution}

South Africa (KwaZulu-Natal, Mpumalanga). 
Amblypsilopus mufindiensis species group

\section{Diagnosis}

The Amblypsilopus mufindiensis species group is here created for the two newly described species, differing from all other Afrotropical species of the genus in very long bristles on the antennal pedicel and mesonotum; the scutellum bears 15-20 long dorsal and marginal cilia in addition to pair of strong setae; all femora have rows of very long setae or hairs, and mid tarsi are covered with elongate setulae. However, the other morphological characters are similar to those in A. bevisi, a member of Amblypsilopus fasciatus species group. Therefore, the A. mufindiensis species group must be also considered a part of the A. pallidicornis lineage as defined by Bickel (1994).

\section{Notes}

Amblypsilopus mufindiensis and A. martini compose the A. mufindiensis species group, both species found on the Tanzanian highlands at a distance of about $400 \mathrm{~km}$ from each other.

Amblypsilopus mufindiensis sp. nov. urn:1sid:zoobank.org:act:45947AE2-E7E0-4779-BF34-7D63FDA9C655

Fig. 5

\section{Diagnosis}

Amblypsilopus mufindiensis sp. nov. is very close to A. martini sp. nov. in habitus, differing distinctly by its mid tarsomeres 3-5 bearing only black elongate setulae (Fig. 5E). The male of Amblypsilopus martini sp. nov. has white and black elongate setulae on the mid tarsomeres 3-5 (Fig. 6F). The length ratio of the mid tarsomeres is different in the two species.

\section{Etymology}

The species is named after the Mufindi Highlands located near the town of Iringa.

\section{Material examined}

Holotype

TANZANIA - ${ }^{\wedge}$; Iringa Region, Mufindi Highland Lodge; $8^{\circ} 36^{\prime}$ S, $35^{\circ} 17^{\prime}$ E; alt. 950 m; 20-22 Nov. 2009; T. Pape and S.A. Marshall leg.; ZMUC.

\section{Description}

Male (Fig. 5A)

MeAsurements. Body length $6 \mathrm{~mm}$; antenna length $1.8 \mathrm{~mm}$; wing length $7 \mathrm{~mm}$; wing width $1.9 \mathrm{~mm}$.

HEAD (Fig. 5B). Frons shining bluish green; no anterior vertical seta; 1 strong postvertical bristle; upper postocular setae black, short; lateral postocular setae white, uniserial; ventral postcranium densely covered with long irregular white hairs; face shining blue-green, silvery-white pollinose at clypeus and eye margins, broad, strongly bulging, as wide as high, under antennae 4.5 times as wide as postpedicel; clypeus densely covered with short white hairs, large, wider than high $\left({ }^{4} / 3\right)$, separated from eyes; antenna (Fig. 5C) black, $1 / 3$ as long as body; scape widened, with inner projection; pedicel rounded, with 4-5 very long dorsal, ventral and outer bristles, with short inner bristles; postpedicel rounded-triangular, as long as high (12/11), with short dense hairs; arista-like stylus dorsal, microscopically haired; length (mm) of scape, pedicel, postpedicel, stylus (segments 1 and 2), 0.10/0.09/0.11/0.06/1.54; proboscis orange; palpus black, with white hairs and 2-3 long black bristles. 

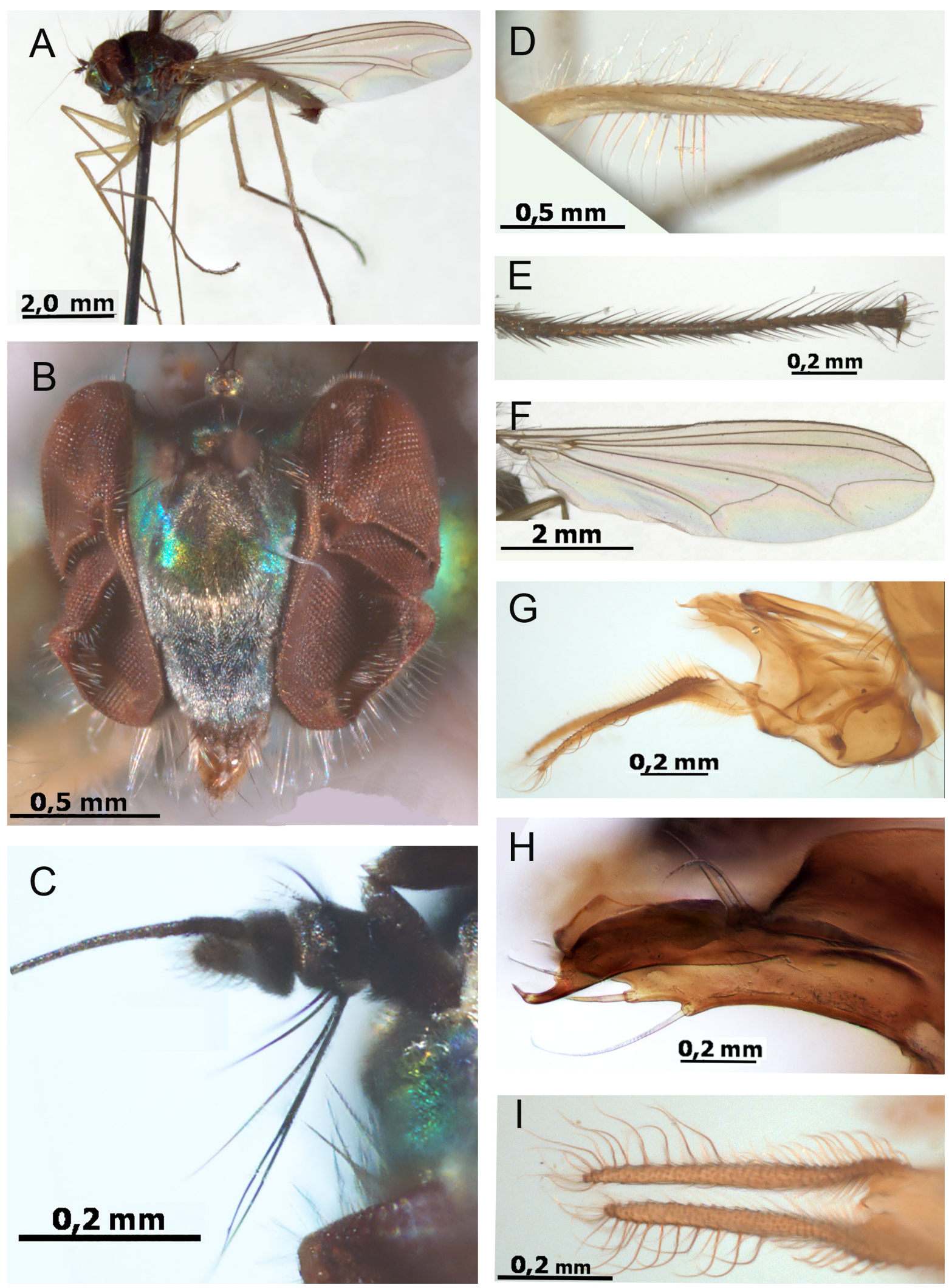

Fig. 5. Amblypsilopus mufindiensis sp. nov., holotype, $\widehat{\jmath}$ (ZMUC). A. Habitus. B. Head. C. Antenna. D. Fore femur. E. Mid tarsus. F. Wing. G. Hypopygium after maceration, left lateral view. H. Surstylus, lateral view. I. Cerci, dorsal view. 
Thorax. Mesonotum and scutellum metallic bluish green; pleura bronze-green, weakly pollinose; all major bristles unusually long; 6 dorsocentral bristles gradually decreasing in size anteriorly with strongest posterior pair (ca $1.5 \mathrm{~mm}$ in length); acrostichals long, biserial; numerous long setae between major bristles, about as long as acrostichals; scutellum with 1 pair of long and strong bristles, 9-10 marginal and 9-10 dorsal long black setae, somewhat shorter than major bristles.

LEGS. Mostly yellow; mid and hind coxae black; tarsi brownish to black from middle of basitarsi; all coxae with numerous long white hairs; fore coxa with 3 black subapical setae; fore femur (Fig. 5D) with anteroventral row of 10-12 long black setae on basal half, with complete posterior and posteroventral rows of long white setae becoming black at apex; all setae about 2 times as long as fore femur height; fore tibia and tarsus without remarkable setae or hairs; mid femur with anterior row of white setae on basal $2 / 3$, as long as femur height, with complete posterior and posteroventral rows of white setae becoming black at apex, about 2 times as long as mid femur height; mid tibia with 3 short anterior setae, without ventral setae; mid tarsus simple, with tarsomeres $2-5$ with anterior and posterior rows of elongate black setulae (Fig. 5E); hind femur with posterior row of white setae on basal $1 / 3$, about 2 times as long as femur height; hind tibia with 2 anterodorsals, several short posterodorsal and ventral setae; femur, tibia and tarsomere (from first to fifth) length ratio (mm): fore leg: 1.67/1.8/1.94/0.61/0.48/0.3/0.19, mid leg: 2.19/3.18/2.96/ 0.88/0.54/0.48/0.14, hind leg: 2.52/3.63/1.9/0.99/0.62/0.35/0.2.

WING (Fig. 5F). Almost hyaline, veins brown; $\mathrm{R}_{4+5}$ gently curved to $\mathrm{M}_{1}$ on apical third; $\mathrm{M}_{1+2}$ straight on basal half, then slightly convex anteriad; $\mathrm{M}_{1}$ with strong elbow, forming right angle with $\mathrm{M}_{1+2}$; ratio of parts of costa between $\mathrm{R}_{2+3}$ and $\mathrm{R}_{4+5}$ to those between $\mathrm{R}_{4+5}$ and $\mathrm{M}_{1}, 4 / 1$; crossvein dm-m weakly sinuate; ratio of crossvein $\mathrm{dm}-\mathrm{m}$ to apical part of $\mathrm{M}_{1+2}$ (fork-handle) to apical part of $\mathrm{M}_{4}, 114 / 84 / 41$; anal vein and lobe distinct; anal angle acute; alula present; lower calypter yellow with black apex, with fan of long white setae; halter yellow.

ABDomen. Thin, slightly longer than head and thorax combined, mostly shining dark green, black posteriorly along sutures, with short black hairs and long marginal bristles; segment 1 with long white hairs; hypopygium (Fig. 5G) black, with blackish brown appendages; cercus (Fig. 5I) black, brown at base, simple, 1.5 times as long as epandrium, broader at base, gradually narrowed towards apex, with long black outer bristles, densely covered with long light hairs along entire length ventrally, covered with hairs at base dorsally; surstylus (Fig. 5H) elongate, bilobate, with inner lobe cut apically, bearing 2 strong pedunculate setae dorsally, with outer lobe hooked at apex, with short apical spine and 2 subapical setae ventrally; 2 long pedunculate epandrial setae at base of surstylus.

\section{Female}

Unknown.

\section{Ecology}

According to the type specimen label, imagos inhabit mountain area at $950 \mathrm{~m}$ above sea level between the Ruaha National Park and Udzungwa Mt National Park in central Tanzania.

$$
\begin{gathered}
\text { Amblypsilopus martini sp. nov. } \\
\text { urn:1sid:zoobank.org:act:CBC7B34B-C9FE-4909-9573-0293F5F38049 }
\end{gathered}
$$

Fig. 6

\section{Diagnosis}

Amblypsilopus martini sp. nov. is very close to A. mufindiensis sp. nov. in habitus, differing distinctly by its mid tarsomeres 3-5 bearing white and black elongate setulae (Fig. 6F). The male of Amblypsilopus mufindiensis sp. nov. has only black elongate setulae on the mid tarsomeres 3-5 (Fig. 5E). 


\title{
Etymology
}

The species is named for one of the collectors of the types, Dr O. Martin (ZMUC).

\section{Material examined}

\section{Holotype}

TANZANIA - O'; East Uzambara, Amani; alt. 1000 m; 2 Feb. 1977; O. Lomholdt and O. Martin leg.; ZMUC.

\section{Paratypes}

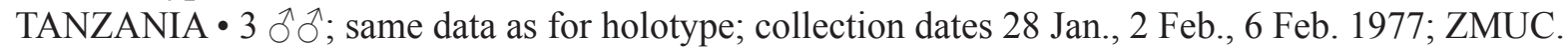

\section{Description}

\author{
Male (Fig. 6A)
}

Similar to A. mufindiensis sp. nov. in all respects except as noted.

Measurements. Body length 6.5-7 mm; antenna length $1.6 \mathrm{~mm}$; wing length $6.5-7 \mathrm{~mm}$; wing width $1.6 \mathrm{~mm}$.

HEAD (Fig. 6B). Face shining blue-green, silvery-white pollinose at clypeus, broad, strongly bulging, 1.3 times as wide as high, under antennae 3.6 times as wide as postpedicel; clypeus shining, covered with short white hairs at eye margins mainly, large, as wide as high, separated from eyes; antenna (Fig. 6C) black, $1 / 4$ as long as body; postpedicel rounded-triangular, slightly shorter than high (11/13); length (mm) of scape, pedicel, postpedicel, stylus (segments 1 and 2), 0.12/0.07/0.11/0.05/1.3.

Thorax. Scutellum with 1 pair of long and strong bristles, 9-10 marginal and 4-6 dorsal long black setae, distinctly shorter than major bristles.

Legs. Mostly yellow; mid and hind coxae black; tarsi brownish to black from tip of basitarsi; fore femur (Fig. 6E) with anteroventral row of 4 long black setae at base, about 2 times as long as femur height, with almost complete posterior and posteroventral rows of white setae becoming black at apex, 1.5-2 times as long as femur height; mid femur (Fig. 6G) with anterior row of white setae on basal $2 / 3$, as long as femur height, with almost complete posterior and posteroventral rows of white setae, 1.5-2 times as long as mid femur height; mid tibia with 2-3 short anterior setae, without ventral setae; mid tarsus simple, with tarsomeres 3-5 with anterior rows of elongate white and black setulae (Fig. 6F); hind femur with posterior row of white setae on basal $1 / 3,1.5-2$ times as long as femur height; femur, tibia and tarsomere (from first to fifth) length ratio (mm): fore leg: 1.69/1.76/1.81/0.59/0.47/0.31/0.18, mid leg: 1.86/3.28/2.98/0.74/0.43/0.32/0.15, hind leg: 2.53/3.62/1.75/0.81/0.51/0.31/0.18.

WING (Fig. 6D). Ratio of parts of costa between $\mathrm{R}_{2+3}$ and $\mathrm{R}_{4+5}$ to those between $\mathrm{R}_{4+5}$ and $\mathrm{M}_{1}, 3 / 1$; crossvein $\mathrm{dm}-\mathrm{m}$ weakly sinuate; ratio of crossvein $\mathrm{dm}-\mathrm{m}$ to apical part of $\mathrm{M}_{1+2}$ (fork-handle) to apical part of $\mathrm{M}_{4}$, 109/76/34.

АвDомen. Thin, 1.4 times as long as head and thorax combined, mostly shining greenish violet, black posteriorly along sutures; hypopygium (Fig. 6H) black, with black appendages; cercus simple, 1.3 times as long as epandrium, broader at base, gradually narrowed towards apex, with long black outer bristles, densely covered with long brownish hairs along entire length ventrally, covered with hairs at base dorsally; surstylus (Fig. 6I) elongate, bilobate, looking like trilobate; inner lobe of surstylus with short apical process and short subapical setae; outer lobe of surstylus with short apical spine and short subapical setae, with long mid-dorsal arm bearing 2 strong apical setae; 2 long pedunculate epandrial setae at base of surstylus. 


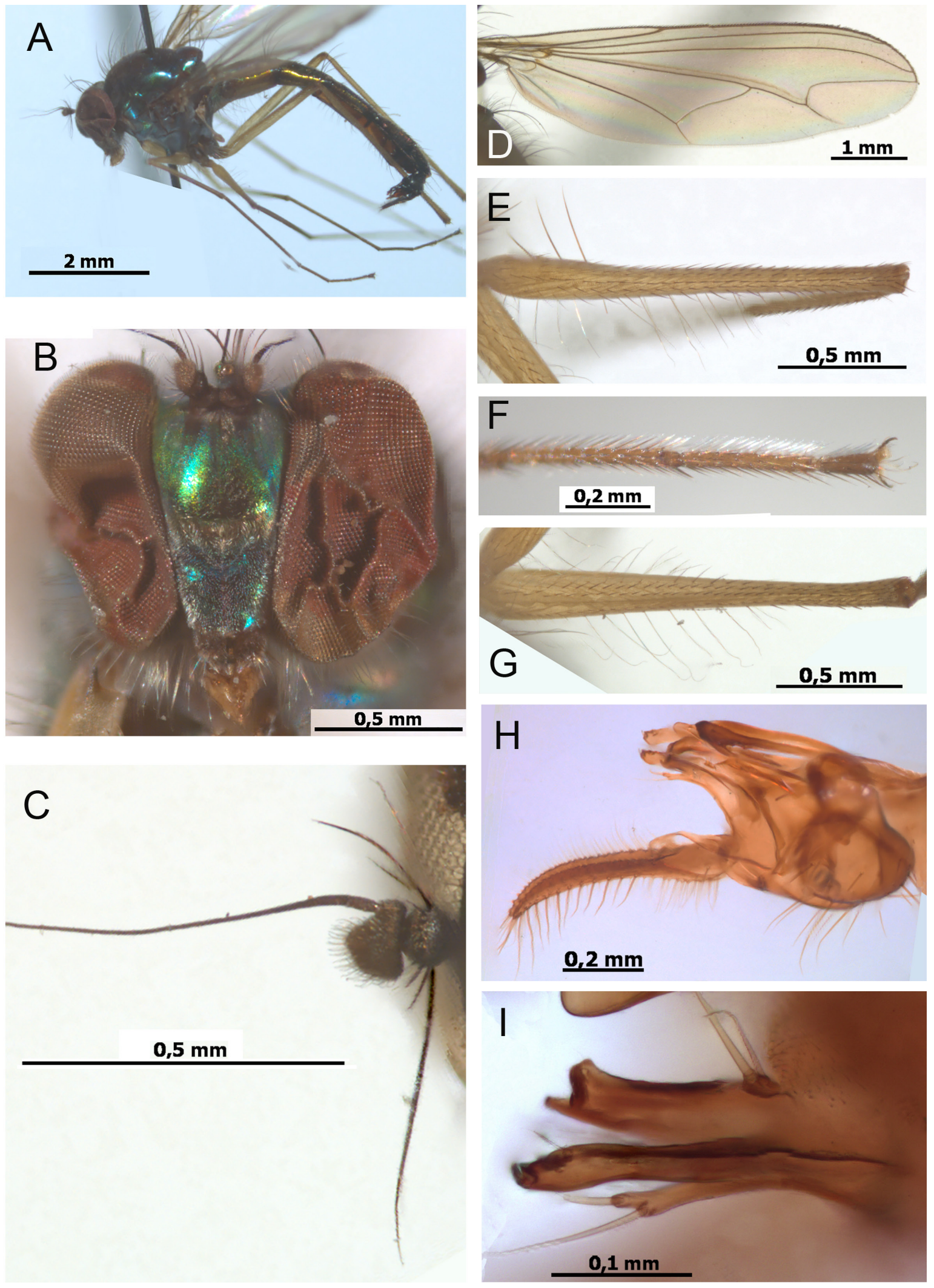

Fig. 6. Amblypsilopus martini sp. nov., holotype, §ิ (A-G: ZMUC); paratype, ô (H-I: ZMUC). A. Habitus. B. Head. C. Antenna. D. Wing. E. Fore femur. F. Mid tarsus. G. Mid femur. H. Hypopygium after maceration, left lateral view. I. Surstylus, lateral view. 
Female

Unknown.

\section{Ecology}

According to type specimen labels, imagos inhabit forested area of the Amani Nature Reserve at $1000 \mathrm{~m}$ above sea level in the East Usambara Mountains of northeastern Tanzania.

\section{Ungrouped species}

Amblypsilopus basilewskyi (Vanschuytbroeck, 1960)

Sciapus basilewskyi Vanschuytbroeck, 1960:319. Type locality: Tanzania: Tanganyika Terr., Kilimanjaro, Marangu, Versant S.E.

Amblypsilopus basilewskyi - Bickel 1994: 373. — Grichanov 1996: fig. 3.

\section{Material examined}

KENYA $\bullet 2 \widehat{\partial}$ (specimens in ethanol); Kakamega Forest; $0^{\circ} 22^{\prime} \mathrm{S}, 34^{\circ} 50^{\prime} \mathrm{E}$; alt. $1500 \mathrm{~m}$; mid-Sep.mid-Oct. 2001; Bergsdorf and Kraemer leg.; Malaise trap; NMSA • $3 \widehat{\jmath} \widehat{\jmath}$; Kikuyu env., Ondri wetland; $1.25595^{\circ} \mathrm{S}, 36.66557^{\circ} \mathrm{E}$; alt. $2014 \mathrm{~m} ; 12-14$ Nov. 2012; D. Gavryushin leg., forest; ZMUM • 1 ○ं; Kikuyu env., Ondri wetland; $1.25697^{\circ}$ S, 36.66682 ${ }^{\circ}$ E; alt. 2001 m; 15 Nov. 2012; D. Gavryushin leg., ZMUM $-1{ }^{\top}$; Central Province, Katura Forest, Nairobi; $1^{\circ} 14.504^{\prime}$ S, 36 $49.452^{\prime}$ E; alt. 1720 m; 23 Apr. 2011; A.H. Kirk-Spriggs leg.; sweeping in shaded mixed upland indigenous forest; BMSA.

\section{Distribution}

DR Congo, Ethiopia, Kenya, Tanzania, Uganda.

\section{Notes}

Having broad male face, elongate antenna and trilobate cercus, the species is close to some species of the Madagascan Amblypsilopus pallidicornis species group (Grichanov 2021a).

\section{Amblypsilopus bipectinatus (Parent, 1934)}

Sciapus bipectinatus Parent, 1934: 120. Type locality: Kenya: Nairobi.

Amblypsilopus bipectinatus - Bickel 1994: 373.

\section{Material examined}

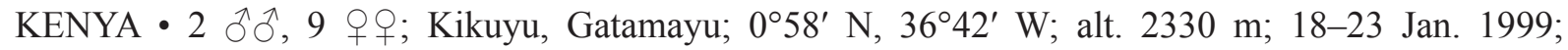
Th. Wagner leg.; ZFMK • $31 \partial^{\top}{ }^{\top}, 19$ 우; Mt Kenya, NP-HQ; $0^{\circ} 10.5^{\prime} \mathrm{N}, 37^{\circ} 8.8^{\prime} \mathrm{W}$; alt. $2550 \mathrm{~m}$; Feb.

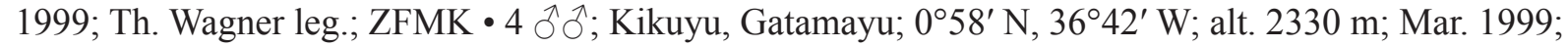
Th. Wagner leg.; ZFMK • 3 ô $^{\top}$; Nyahururu env., Ngare Naro forest; $0.047264^{\circ} \mathrm{N}, 36.377169^{\circ} \mathrm{E}$; alt. 2410 m; 25-26 Nov. 2012; D. Gavryushin leg.; ZMUM.

\section{Remarks}

Having strong vertical bristles on male frons and modified claws on male fore tarsus, the species is close to Chinese species of the genus Sinosciapus Yang, 2002 (Yang \& Zhu 2011). However, the latter was diagnosed by two rather than one pairs of scutellar bristles, by one modified claw on the male fore tarsus rather than both claws modified.

\section{Distribution}

Kenya. 
Amblypsilopus cuthbertsoni (Parent, 1937)

Sciapus cuthbertsoni Parent, 1937: 129. Type locality: Zimbabwe: Salisbury.

Amblypsilopus cuthbertsoni - Bickel 1994: 373.

\section{Material examined}

TANZANIA • 1 $\widehat{\partial}$ (specimen in ethanol); Morogoro Reg., Udzungwa Mt National Park, Mito Mitatu; 750'15.1" S, 3650'49.9" E; alt. 1198 m; 31 May 2013; T. Pape and N. Scharff leg.; Malaise trap No. 2; ZMUC.

\section{Distribution}

Burundi, Zimbabwe. First record from Tanzania.

\section{Amblypsilopus knorri Grichanov, 1999}

Amblypsilopus knorri Grichanov, 1999: 131. Type locality: Cameroon: Muell.

\section{Material examined}

IVORY COAST • 4 $\widehat{\partial}, 3$ 우 (specimens in ethanol); W Abidjan, CSRS [Swiss Centre for Scientific Research in Côte d'Ivoire], Adiapo-Doumé; 5²1' N, 401' W; 22 Feb.-3 Mar. 1998; Kassebeer and Hilger leg.; Malaise trap; ZMUK.

\section{Distribution}

Cameroon. First record from Ivory Coast.

\section{Amblypsilopus nartshukae Grichanov, 1996}

Amblypsilopus nartshukae Grichanov, 1996: 290. Type locality: Angola, 2 miles S Luanda.

\section{Material examined}

GABON・3 ふぇ, 2 우 (specimens in ethanol); Libreville; Nov. 1984; A. Pauly leg.; RBINS.

\section{Distribution}

Angola, Gabon, Ivory Coast.

Amblypsilopus udzungwensis sp. nov. urn:1sid:zoobank.org:act:B1A036BA-69DC-4515-9EC0-7F29CA9E7428

Fig. 7

\section{Diagnosis}

Amblypsilopus udzungwensis sp. nov. keys to A. nartshukae (see above), differing from the latter in the conoid postpedicel with apical arista-like stylus (Fig. 7C); the mid tibia with erect ciliation, the cercus with large middorsal tooth (Fig. 7H). The male of $A$. nartshukae is distinguished by the oval postpedicel with a dorsoapical arista-like stylus, the mid tibia without erect ciliation and the cercus with small distodorsal apophysis.

\section{Etymology}

The species is named after the Udzungwa Mt National Park in the Morogoro Region of Tanzania, where the type was collected. 


\title{
Material examined
}

Holotype

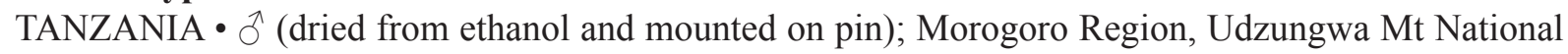
Park, Mito Mitatu; 750'22.7" S, 3650'42.8' E; 25 Nov. 2013; alt. 1235 m; T. Pape and N. Scharff leg.; Malaise trap \#3; ZMUC.

\section{Description}

\author{
Male (Fig. 7A)
}

Measurements. Body length $4.3 \mathrm{~mm}$; antenna length $1.3 \mathrm{~mm}$; wing length $3.8 \mathrm{~mm}$; wing width $1 \mathrm{~mm}$.

HEAD (Fig. 7B). Frons greenish violet, shining; 1 black anterior vertical hair; 1 strong postvertical bristle; upper postocular setae black, short; lateral postocular setae white, uniserial; ventral postcranium covered with long irregular white hairs; face densely silvery-white pollinose, metallic under antennae, narrow, 2 times higher than clypeus, 1.8 times as high as wide under antennae, 5.5 times as high as wide at clypeus, at clypeus as wide as postpedicel; clypeus small, slightly bulging; antenna (Fig. 7C) nearly $1 / 3$ as long as body, black; scape swollen, vase-like; pedicel rounded, with ring of short bristles, 1 long dorsal bristle; postpedicel conoid, 2 times as long as high, with short hairs; arista-like stylus black, apical, glabrous, bi-segmented; length ( $\mathrm{mm}$ ) of scape, pedicel, postpedicel, stylus (segments 1 and 2), 0.06/0.06/0.15/0.04/1.01; proboscis and palpus orange-brown, with yellow and black hairs.

Thorax. Mesonotum and scutellum shining green-violet; pleura black, white pollinose; 2 strong posterior dorsocentral bristles and 3 hair-like setae anteriorly (mostly broken); acrostichals strong, 3 pairs; scutellum with 2 strong bristles and 2 minute setae laterally.

Legs. Mostly yellow; mid and hind coxae brown, fore leg brown from middle of tibia, mid and hind tarsi brownish to brown from middle of basitarsi; fore and mid coxae with white hairs and 2-3 brownish subapical setae; hind coxa with 1 brown bristle and 2-3 fine yellow setae at middle; fore femur with few long hairs at base; fore and mid tarsi (Fig. 7D-E) and mid tibia with rows of elongate semi-erect setulae, as long as podomere width; hind leg without remarkable setae or hairs; tarsomere 5 of all tarsi distinctly flattened and slightly widened; femur, tibia and tarsomere (from first to fifth) length ratio $(\mathrm{mm})$ : fore leg: 1.11/1.35/1.35/0.41/0.28/0.16/0.1, mid leg: 1.4/2.02/1.14/0.61/0.39/0.24/0.19, hind leg: $1.71 / 2.41 /$ $1.13 / 0.55 / 0.34 / 0.16 / 0.16$.

WING (Fig. 7F). Almost hyaline, veins brown; $R_{4+5}$ gently curved to $M_{1}$ on apical third; $M_{1+2}$ almost straight; $M_{1}$ with strong elbow, forming right angle with $\mathrm{M}_{1+2}$; ratio of parts of costa between $\mathrm{R}_{2+3}$ and $\mathrm{R}_{4+5}$ to those between $\mathrm{R}_{4+5}$ and $\mathrm{M}_{1}, 37 / 8$; crossvein $\mathrm{dm}-\mathrm{m}$ almost straight; ratio of crossvein $\mathrm{dm}-\mathrm{m}$ to apical part of $\mathrm{M}_{1+2}$ (fork-handle) to apical part of $\mathrm{M}_{4}, 40 / 73 / 14$; anal lobe reduced; anal vein and angle absent; lower calypter yellow with white hairs; halter yellow.

AвDomen. Thin, 1.7 times as long as head and thorax combined, with black hairs and marginal setae; unmodified segments mostly shining green, black posteriorly along sutures, with black lateral spots; segments 6 and 7 black; segment 8 with short hairs; hypopygium and its appendages (Fig. 7G) brownblack; cercus as long as epandrium, broad on basal third, narrow on distal third, with black setae dorsally, with narrow dorsal process at basal third and small dorsal tubercle at distal third (Fig. 4H); surstylus projected, broad, subtriangular, with small distodorsal process, with few long dorsal and distal setae; 1 long pedunculate and 2 short epandrial setae.

\section{Female}

Unknown. 

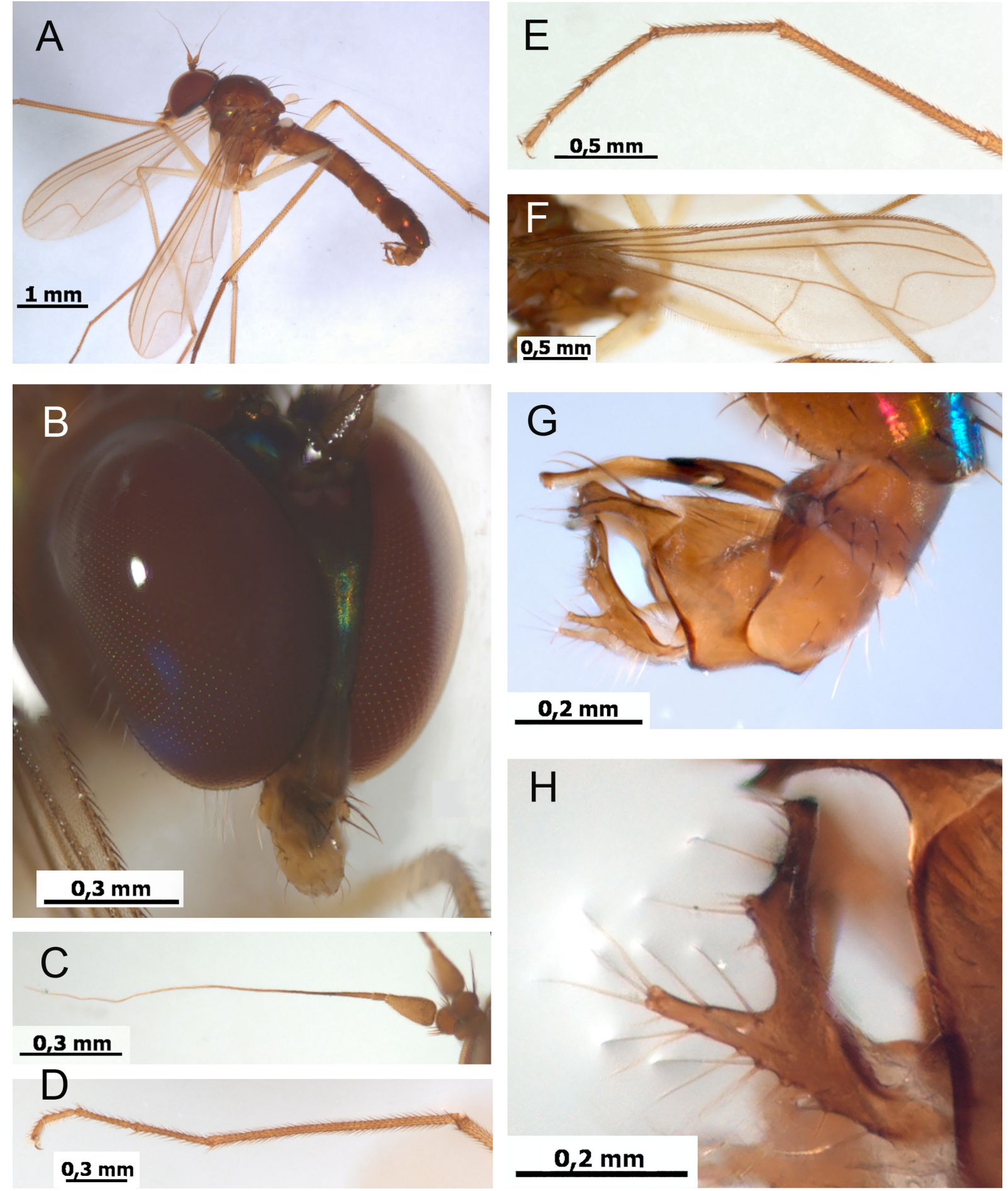

Fig. 7. Amblypsilopus udzungwensis sp. nov., holotype, ô (ZMUC). A. Habitus. B. Head. C. Antenna. D. Foretarsus. E. Mid tarsus. F. Wing. G. Hypopygium after maceration, left lateral view. H. Surstylus, lateral view. 


\section{Discussion}

Bickel (1994) listed 33 Afrotropical Amblypsilopus species in his monograph. Since then 15 species from this list were removed from the genus, synonymized or declared nomina dubia. As a result of research from 1996 to 2022, the number of species of the genus has increased from 18 to 66, i.e., 37 recognizable species known from continental Africa and 28 species known from Madagascar and adjacent islands (with one shared species). Bickel (1994, 2009, 2019) erected many species groups for the Australasian and Oriental Amblypsilopus species. These groups are often extremely peculiar in MSSC, occurring sometimes very locally. Yang et al. (2011) recognized five of Bickel's species groups in the Chinese fauna, including the A. abruptus species group and the A. pallidicornis species group. Bickel (1994) noted the presence of the A. abruptus species group and the A. pallidicornis species group in the Afrotropical region and created the A. fasciatus species group for the former South African genus Sciopolina and the A. lenga species group for a single West African species A. lenga kept earlier in the genus Labeneura Parent, 1937. Grichanov (2021a) divided the Madagascan species into three groups, i.e., the A. abruptus species group (6 species), the A. pallidicornis species group (15 species) and the $A$. stuckenbergi species group (7 species). Continental Afrotropical species are associated with the Pantropical A. abruptus species group (11 species), southern African A. fasciatus species group (7 species) and the Tanzanian A. mufindiensis species group with two known species. The other known species are considered ungrouped.

The Afrotropical Amblypsilopus species are very diverse morphologically, with MSSC sometimes unique for the genus. Male wing veins $\mathrm{R}_{2+3}$ and $\mathrm{R}_{4+5}$ are fused apically in five species of the $A$. fasciatus species group. The male of Amblypsilopus lenga is peculiar in vein $\mathrm{M}_{1+2}$ modification differing from that in other genera of Sciapodinae (Bickel 1994), and palpus ornamentation differs from that in the New Guinean A. megastoma species group (Bickel 2019). The Madagascan endemics A. andasibensis Grichanov, 2021 and $A$. freidbergi Grichanov, 2021 are remarkable in having symmetrical male abdominal segments 7 and 8 and basal epandrial foramen; the characters were used for separation of some genera of Medeterinae Lioy, 1864 or even the subfamily Babindellinae Bickel, 1987 (Bickel 1987; Grichanov 2019 and references cited therein). In Sciapodinae, the hypopygial foramen is usually left lateral in position, but basal in almost all species of the genus Dytomyia Bickel, 1994 (Bickel 1994; Grichanov 1998). The Tanzanian endemics A. mufindiensis sp. nov. and A. martini sp. nov. bear on the mesonotum and scutellum numerous long setae and cilia between major bristles, which are also unusually long, in addition to very long setae on femora and antennal pedicel. Amblypsilopus spiniscapus sp. nov. from Ivory Coast and A. gabonensis sp. nov. from Gabon are striking in their antennal scape with 2-3 strong dorsal bristles, probably the first such example in Sciapodinae. The presence of dorsal setae on the scape is the main character of the subfamily Dolichopodinae Latreille, 1809, although also found in all or some species of four genera of Sympycninae Aldrich, 1905 (Anepsiomyia Bezzi, 1902, Ceratopos Vaillant, 1952, Hercostomoides Meuffels \& Grootaert, 1997, and Syntormon Loew, 1857), in some species of Diaphorinae Schiner, 1864 (Argyra Macquart, 1834) and also in Hydrophorinae Lioy, 1864 (Diostracus Loew, 1861).

The Afrotropical Amblypsilopus is more diverse in Madagascar (25 species), southern African countries (e.g., 10 species are known in South Africa, and 6 species in Zimbabwe) and central African countries (e.g., 11 are known in DR Congo, 8 species occur in Tanzania, 5 species in Kenya). Some species have been found in seven to twelve countries, e.g., A. auratus, A. cilifrons, A. longifilus and A. munroi (all from the A. abruptus species group). Most of the other species (including almost all Madagascan species) are known only from their type localities.

I suspect that the Amblypsilopus fauna of the Afrotropical region will continue to increase significantly in the future. Biodiversity hotspots in this region are well represented in European and American museum dolichopodid collections, which remain unstudied. The high species diversity of tropical fauna and high 
variability of morphological characters testify to a recent origin, active speciation and dispersal of the genus or at least some of the species groups defined within the Amblypsilopus.

\section{Acknowledgements}

The author is sincerely grateful to Drs Patrick Grootaert (RBINS), C.F. Kassebeer (ZMUK), Ashley H. Kirk-Spriggs (presently at the Natural History Museum, London, UK), Mike Mostovsky (presently at the SMNHTAU), Thomas Pape (ZMUC), N.E. Vikhrev and A.L. Ozerov (ZMUM), Thomas Wagner (ZFMK) for providing the specimens studied in this research. The work was funded by RFBR and NSFC according to the research project No. 20-54-53005. The comparative analysis of morphological characters and the preparation of illustrations were performed within the Program for Basic Scientific Research of the Government of the Russian Federation, project No.0665-2019-0014.Two anonymous reviewers kindly commented on earlier drafts of the manuscript.

\section{References}

Becker T. 1923. Dipterologische Studien. Dolichopodidae. D. Aethiopische Region. Entomologische Mitteilungen 12: 1-50.

Bickel D.J. 1987. Babindellinae, a new subfamily of Dolichopodidae (Diptera) from Australia, with a discussion of symmetry in the dipteran male postabdomen. Entomologica Scandinavica 18: 97-103. https://doi.org/10.1163/187631287X00061

Bickel D.J. 1994. The Australian Sciapodinae (Diptera: Dolichopodidae), with a review of the Oriental and Australasian faunas, and a world conspectus of the subfamily. Records of the Australian Museum Supplement 21: 1-394. https://doi.org/10.3853/j.0812-7387.21.1994.50

Bickel D.J. 2009. Amblypsilopus (Diptera: Dolichopodidae: Sciapodinae) from the Southwest Pacific, with a focus on the radiation in Fiji and Vanuatu. In: Evenhuis N.L. \& Bickel D.J. (eds) Fiji Arthropods XIII. Bishop Museum Occasional Papers 103: 3-61.

Bickel D.J. 2019. The Amblypsilopus amnoni and megastoma groups in New Guinea (Diptera: Dolichopodidae: Sciapodinae). Israel Journal of Entomology 49 (2): 195-214.

https://doi.org/10.5281/zenodo.3522860

Cumming J.M. \& Wood D.M. 2017. 3. Adult morphology and terminology. In: Kirk-Spriggs A.H. \& Sinclair B.J. (eds) Manual of Afrotropical Diptera. Volume 1. Introductory Chapters and Keys to Diptera Families: 89-134. Suricata 4, SANBI Graphics \& Editing, Pretoria.

Curran C.H. 1924. The Dolichopodidae of South Africa. Annals of the Transvaal Museum 10 (4): 212232.

Curran C.H. 1926. The Dolichopodidae of the South African Museum. Annals of the South African Museum 23: 377-416.

Curran C.H. 1927. New Dolichopodidae from the Ethiopian Region. Annals and Magazine of Natural History Series 9 19: 1-16. https://doi.org/10.1080/00222932708633569

Grichanov I.Ya. 1996. Four new species of the genus Amblypsilopus Bigot (Diptera: Dolichopodidae) from Tropical Africa and Papua New Guinea. International Journal of Dipterological Research 7 (4): 285-294.

Grichanov I.Ya. 1998. New data on Sciapodinae (Diptera: Dolichopodidae) with a revised catalogue and keys to afrotropical species. Bulletin de l'Institut royal des Sciences naturelles de Belgique, Entomologie 68: 79-130.

Grichanov I.Ya. 1999. New species and new records of Afrotropical Sciapodinae(Diptera: Dolichopodidae). Bulletin de l'Institut royal des Sciences naturelles de Belgique, Entomologie 69: 113-135. 
Grichanov I.Ya. 2011. An illustrated synopsis and keys to afrotropical genera of the epifamily Dolichopodoidae (Diptera: Empidoidea). Priamus Supplement Ankara 24: 1-98.

Grichanov I.Ya. 2017. Alphabetic List of Generic and Specific Names of Predatory Flies of the Epifamily Dolichopodoidae (Diptera). $2^{\text {nd }}$ Ed. All-Russian Institute of Plant Protection, St Petersburg.

https://doi.org/10.5281/zenodo.884863

Grichanov I.Ya. 2018. An Annotated Catalogue of Afrotropical Dolichopodoidae (Diptera). All-Russian Institute of Plant Protection, St Petersburg. https://doi.org/10.5281/zenodo.1187006

Grichanov I.Ya. 2019. Discovery of Udzungwomyia Grichanov in South Africa and definition of a new tribe Udzungwomyiini (Diptera: Dolichopodidae). Israel Journal of Entomology 49 (2): 267-275.

https://doi.org/10.5281/zenodo.3562003

Grichanov I.Ya. 2020a. New records of Dolichopodidae (Diptera) from Russian Primorye and notes on some Chinese species. Russian Entomological Journal 29 (4): 432-438.

https://doi.org/10.15298/rusentj.29.4.12

Grichanov I.Ya. 2020b. Afrotropical Dolichopodoidae (Diptera) catalogue: changes and corrections. Amurian Zoological Journal 12 (4): 406-411. https://doi.org/10.33910/2686-9519-2020-12-4-406-411

Grichanov I.Ya. 2021a. Eleven new species of Amblypsilopus Bigot (Diptera: Dolichopodidae: Sciapodinae) and a key to the species of Madagascar and adjacent islands. European Journal of Taxonomy 755 (1): 47-87. https://doi.org/10.5852/ejt.2021.755.1399

Grichanov I.Ya. 2021b. New species and new records of the Afrotropical Sciapodinae (Diptera: Dolichopodidae). Proceedings of the Russian Entomological Society 92: 42-65. https://doi.org/10.1016/10.47640/1605-7678_2021_92_42

Grichanov I.Ya. \& Brooks S.E. 2017. 56. Dolichopodidae (long-legged dance flies). In: KirkSpriggs A.H. \& Sinclair B.J. (eds) Manual of Afrotropical Diptera, Volume 2. Nematocerous Diptera and Lower Brachycera: 1265-1320. Suricata 5. SANBI Graphics \& Editing, Pretoria.

Grichanov I.Ya., Kirk-Spriggs A.H. \& Grootaert P. 2011. New records of Dolichopodidae (Diptera: Empidoidea) from the Democratic Republic of Congo. CESA News 64: 12-22.

Irwin M.E. 1974. An account of southern African genus Sciopolina with descriptions of new species (Diptera: Dolichopodidae: Sciapodinae). Annals of the Natal Museum 22: 221-264.

Parent O. 1929. Étude sur les Dolichopodides exotiques de la Collection von Röder. Annales de la Société scientifique de Bruxelles (B) 49: 169-246.

Parent O. 1931. Quelques Dolichopodides nouveaux conservés au British Museum. Annales de la Société scientifique de Bruxelles (B) 51: 39-47.

Parent, O. 1933. Etude sur les diptères dolichopodides exotiques du Musee du Congo (Tervuren). Revue de Zoologie et de Botanique africaines 24: 1-49.

Parent O. 1934. Additions à la faune éthiopienne (Diptères: Dolichopodidés). Bulletin de la Société royale entomologique d'Égypte 18: 112-138.

Parent O. 1935. Diptères Dolichopodides Nouveaux. Encyclopédie entomologique (B II) Diptera 8: 59-96.

Parent O. 1936. Diptères Dolichopodidés du Congo belge conservés au Muséum royal d'histoire naturelle de Belgique. Bulletin du Musée royal d'Histoire naturelle de Belgique 12 (15): 2-19.

Parent O. 1937. Diptères Dolichopodides espèces et localités nouvelles. Bulletin et Annales de la Société royale entomologique de Belgique 77: 125-148. 
Parent O. 1941. Diptères Dolichopodides de la région Indo-australienne. Espèces et localités nouvelles. Annals and Magazine of Natural History Series 117 (38): 195-235. https://doi.org/10.1080/00222934108527151

Tonguç A. \& Grootaert P. 2013. A new Palaearctic Amblypsilopus species (Insecta, Diptera, Dolichopodidae) from Turkey. Journal of the Entomological Research Society 15 (1): 91-95.

Vanschuytbroeck P. 1960. Diptera (Brachycera, Orthorrhapha): Dolichopodidae. In: Hanström B., Brinck P. \& Rudebeck G. (eds) South African Animal Life. Results of the Lund University Expedition in 1950-1951 Vol. 7: 316-324. Almqvist \& Wiksell, Göteborg, Stockholm, Uppsala.

Yang D. \& Zhu Y. 2011. Sinosciapus from Taiwan with description of a new species (Diptera: Dolichopodidae). ZooKeys 159: 11-18. https://doi.org/10.3897/zookeys.159.2252

Yang D., Zhang L., Wang M. \& Zhu Y. 2011. Fauna Sinica, Insecta, Volume 53, Dolichopodidae. Science Press, Beijing. [In Chinese with English summary.]

Yang D., Zhang L.L. \& Zhang K.Y. 2018. Species Catalogue of China, Volume 2, Animals, Insecta (VI), Diptera (2), Orthorrhaphous Brachycera. Science Press, Beijing.

Manuscript received: 3 June 2021

Manuscript accepted: 15 November 2021

Published on: 25 January 2022

Topic editor: Nesrine Akkari

Section editor: Torbjørn Ekrem

Desk editor: Pepe Fernández

Printed versions of all papers are also deposited in the libraries of the institutes that are members of the EJT consortium: Muséum national d'histoire naturelle, Paris, France; Meise Botanic Garden, Belgium; Royal Museum for Central Africa, Tervuren, Belgium; Royal Belgian Institute of Natural Sciences, Brussels, Belgium; Natural History Museum of Denmark, Copenhagen, Denmark; Naturalis Biodiversity Center, Leiden, the Netherlands; Museo Nacional de Ciencias Naturales-CSIC, Madrid, Spain; Real Jardín Botánico de Madrid CSIC, Spain; Zoological Research Museum Alexander Koenig, Bonn, Germany; National Museum, Prague, Czech Republic. 